\title{
DESIGUALDADE RACIAL E EDUCAÇÃO: UMA ANÁLISE ESTATÍSTICA DAS POLÍTICAS AFIRMATIVAS NO ENSINO SUPERIOR
}

NARA TORRECILHA FERREIRA ${ }^{1}$

ORCID: https://orcid.org/0000-0002-8064-3916

\begin{abstract}
RESUMO: A partir dos anos 2000, começaram a ser implantadas políticas afirmativas no ensino superior brasileiro, visando a ampliação do acesso da população negra a esse nível de ensino, bem como a diminuição das desigualdades raciais. A Lei n ${ }^{\circ}$ 12.711/2012 determinou a adoção da política afirmativa a todas as instituições federais de ensino superior. O presente trabalho propõe a reflexão acerca dessas políticas afirmativas, visando a elaboração de uma análise crítica em relação aos seus resultados, respondendo a seguinte questão: as políticas afirmativas implementadas no ensino superior público brasileiro ajudam a ampliar o acesso à população negra? A pesquisa realizou um rastreamento de políticas afirmativas implementadas e análises de correlação e regressão linear múltipla para avaliar a efetividade das políticas afirmativas raciais, considerando a ampliação do acesso ao ensino superior à população negra.
\end{abstract}

Palavras-chave: Avaliação, efetividade, Ações Afirmativas, Ensino Superior, critério racial.

\section{RACIAL INEQUALITY AND EDUCATION: AN STATISTICAL ANALYSIS OF AFFIRMATIVE ACTIONS IN HIGHER EDUCATION}

\begin{abstract}
From the 2000s, affirmative policies began to be implemented in brazilian higher education, aiming to increase access to the black population at this level of education and the reduction of racial inequalities. The Law $n^{\circ} 12.711 / 2012$ determined the adoption of affirmative policy by all federal institutions of higher education. The present work proposes a reflection about these affirmative policies, aiming to elaborate a critical analysis in relation to their results, answering the question: are the affirmative policies implemented in Brazilian public higher education helping to increase access to the black population? The research used the tracing of affirmative policies implemented and correlation analyzes and multiple linear regression to evaluate the effectiveness of affirmative racial policies, considering the expansion of access to higher education to the black population.
\end{abstract}

Keywords: Evaluation, effectiveness, Affirmative Actions, Higher Education, racial criteria.

\footnotetext{
${ }^{1}$ Fundação Getúlio Vargas (FGV/EAESP). São Paulo, SP, Brasil. <nara.ferreira@fgv.edu.br>
} Educação em Revista|Belo Horizonte|v.36|e227734|2020 


\title{
DESIGUALDAD RACIAL Y EDUCACIÓN: UN ANÁLISIS ESTADÍSTICO DE LAS ACCIONES AFIRMATIVAS EN LA EDUCACIÓN SUPERIOR
}

\begin{abstract}
RESÚMEN: A partir de la década de 2000, las políticas afirmativas comenzaron a implementarse en la educación superior brasileña, con el objetivo de ampliar el acceso a la población negra en este nivel de educación y reducir las desigualdades raciales. La Ley $\mathrm{N}^{\circ}$ 12.711/2012 determinó la adopción de una política afirmativa para todas las instituciones federales de educación superior. Este documento propone una reflexión sobre estas políticas afirmativas, con el objetivo de elaborar un análisis crítico en relación con sus resultados, respondiendo a la pregunta: ¿las políticas afirmativas implementadas en la educación superior pública brasileña ayudan a aumentar el acceso a la población negra? La investigación llevó a cabo el seguimiento de las políticas afirmativas implementadas y los análisis de correlación y regresión lineal múltiple para evaluar la efectividad de las políticas afirmativas raciales, considerando la expansión del acceso a la educación superior para la población negra.
\end{abstract}

Palabras clave: Evaluación, Efectividad, Acciones Afirmativas, Educación Superior, Criterios Raciales.

\section{INTRODUÇÃO}

No Brasil, vários grupos são historicamente marginalizados, e seus membros são excluídos do exercício da cidadania. A democracia racial brasileira, alardeada por anos, assevera a ideia de que as relações de raça no Brasil seriam harmoniosas. No entanto, a vergonha do brasileiro de demonstrar o próprio preconceito não significa que a discriminação racial não exista, dificultando, ainda, o combate ao racismo por inibir discussões abertas sobre o tema. Guarnieri e Melo-Silva (2007) defendem que, no Brasil, o segregacionismo, embora não declarado, é cultuado socialmente de maneira silenciosa e, por isso, a discriminação racial no Brasil encontra meios informais de propagação e é dificilmente assumida.

A sociedade brasileira está estruturada a partir do mito da democracia racial, que teve origem no estabelecimento de uma ordem legal e formal, livre e igualitária. Segundo Alberti e Pereira (2007, p. 93), "faz parte desse mito a ideia de que as relações de raça no Brasil são harmoniosas e que a miscigenação é nossa contribuição à civilização do planeta". Para Oliveira Filho (2009, p.430), o argumento segundo o qual o Brasil seria uma democracia racial é usado frequentemente como "premissa da afirmação de que o diferencialismo racial (ou políticas públicas de caráter diferencialista) não faria sentido no Brasil, uma vez que o país não é caracterizado por divisões baseadas na raça".

Grande parte de nossa intelectualidade continua acreditando que o problema da desigualdade no Brasil é apenas decorrente do fosso entre classes sociais, e não do nosso sistema de castas raciais (ARAÚJO, 2008). Nesse sentido, Pinto (2005) destaca que o debate sobre a implementação das cotas foi marcado pela polarização ideológica. De um lado, utilizava-se o argumento de fluidez das classificações raciais no Brasil como representante de uma visão de mundo "branca" e "negadora da existência do racismo". De outro lado, dados estatísticos sobre as desigualdades econômico-sociais entre brancos e negros eram apresentados como a "prova" da existência de uma sociedade racialmente bipolar com linhas de clivagem racial nítidas entre brancos e negros. No entanto, essa diluição é desmantelada do ponto de vista do acesso a direitos sociais e econômicos, em que fica evidente a diferença das cores predominantes em cada classe social. Diante desta realidade social estruturada pelo mito da democracia racial e pelo ideal de branqueamento, manteve-se intacto o padrão de relações raciais brasileiro, não sendo posto em prática nenhum tipo de política que pudesse efetivamente corrigir as desigualdades raciais.

Moehlecke (2004) ressalta que as políticas de ação afirmativa tratam uma relação complexa de igualdade, que tenciona a tradição moderna baseada nos direitos individuais, ao propor uma redefinição da igualdade de oportunidades liberal, ao introduzir a utilização de particularidades grupais e ao dar uma ênfase positiva à construção de identidades raciais. Alves e Galeão-Silva (2004) defendem uma mudança ideológica no Brasil em que o mito da democracia racial, que nega a existência das discriminações, seja substituído pela ideologia da diversidade administrada, que revela a discriminação para, em seguida, ensinar a tolerância. 
Alberti e Pereira (2005) destacam, como indutores das políticas afirmativas raciais, a relação entre a formação do movimento negro contemporâneo, a efervescência política no fim da ditadura, as agremiações de esquerda e a Igreja Católica, bem como a importância das manifestações artísticas e culturais. Outro ponto importante é a projeção que o movimento ganha por ocasião do centenário da abolição, em 1988, o qual abre espaço para articulações com os poderes públicos (ALBERTI; PEREIRA, 2007). Passa então a existir uma preocupação com o estabelecimento de um estatuto legal com a introdução, na Constituição de 1988, de artigos voltados para direitos raciais.

Em 1995, o Brasil solicitou a cooperação técnica da Organização Internacional do Trabalho (OIT) no sentido de efetivar e implementar políticas que promovessem a igualdade de oportunidades e de tratamento no emprego e na ocupação (ALVES; GALEÃO-SILVA, 2004) depois que o Brasil foi denunciado na OIT pelo descumprimento de sua Convenção 111, de 1968, que proíbe todas as formas de discriminação (racial, de gênero, religiosa etc.) no mercado de trabalho (ALBERTI; PEREIRA, 2007). Embora tenham sido passos importantes, não significavam a efetividade de políticas públicas voltadas para a população negra.

De acordo com Moehlecke (2004), apenas nos anos 2000 a questão racial entrou na agenda política nacional, e as políticas de ação afirmativa direcionadas à população negra espalharam-se pelo País, destacando-se o programa de combate ao racismo apresentado pelo Governo Federal na Conferência Internacional contra o Racismo, Xenofobia e Intolerância, realizado em Durban, na África do Sul, em 2001. Assim, como se verá adiante, algumas instituições públicas de ensino superior começaram a implantar as primeiras políticas de cotas raciais e sociais em seus vestibulares. Em 2005, o Governo Federal implantou nacionalmente o Programa Universidade para Todos (PROUNI), dirigido aos estudantes de renda mais baixa, reservando uma parte das vagas a negros, pardos e indígenas; e, em 2013, foi implantada nacionalmente a reserva de vagas nas instituições públicas federais de ensino superior, por meio da Lei no 12.711/2012.

A fim de analisar em que medida uma política pública pode, efetiva e estruturalmente, colaborar para a redução da desigualdade racial, o presente trabalho propõe-se ao desenvolvimento de uma reflexão acerca das políticas afirmativas implantadas no ensino superior público do Brasil, visando a elaborar uma análise crítica em relação aos resultados dessas políticas em relação à ampliação do acesso à população negra. Será realizada uma análise quantitativa dos resultados dessas políticas afirmativas implementadas a partir dos anos 2000, tanto pelas instituições quanto pelo Governo Federal, com o objetivo de analisar o quanto elas contribuem para a universalização do acesso à educação superior, examinando a relação entre a sua implementação e seus resultados efetivos.

Importante lembrar que os conceitos de efetividade e impacto são muitas vezes confundidos ou tratados como sinônimos. Nesse sentido, cabe esclarecer que a efetividade se refere à consecução dos objetivos, abrangendo a qualidade dos resultados alcançados no curto prazo, especificamente aos efeitos obtidos no programa, enquanto o impacto alude aos resultados de longo prazo, nomeadamente em relação ao público alvo, mas também à população como um todo.

\section{DESIGUALDADE RACIAL E EDUCAÇÃO NO BRASIL: DADOS E LITERATURA}

De acordo com Pereira (2003), negar a desigualdade racial e a existência do racismo é negar a possibilidade de rompimento com identidades nacionais, instituídas sobre bases suspeitas da universalidade dos setores hegemônicos, e de construção de outras, que partam da heterogeneidade. Para Guimarães (1995), na ausência de discriminações raciais institucionalizadas, o racismo brasileiro se reproduz pelo jogo contraditório de uma cidadania definida de modo amplo e garantida por direitos formais, que são largamente ignorados e estruturalmente limitados pela pobreza e pela violência policial cotidiana. Guimarães (1995) afirma que as elites brasileiras podem se orgulhar de possuir a Constituição e a legislação mais progressistas e igualitárias do mundo, pois as leis permanecem, no mais das vezes, inoperantes. Nesse sentido, de acordo com a Pesquisa das características étnico-raciais da população (Pcerp) 2008 (IBGE, 2011), 64\% da população reconhece que a cor ou raça influencia a vida das pessoas. 
A população brasileira é formada predominantemente por brancos, pretos e pardos. Conforme a Pesquisa Nacional por Amostra de Domicílios (PNAD) de 2015, a população negra ${ }^{2}$ totalizava 54\% da população brasileira, conforme Gráfico 1.

Gráfico 1 - Distribuição percentual da população, por cor/raça - 2015

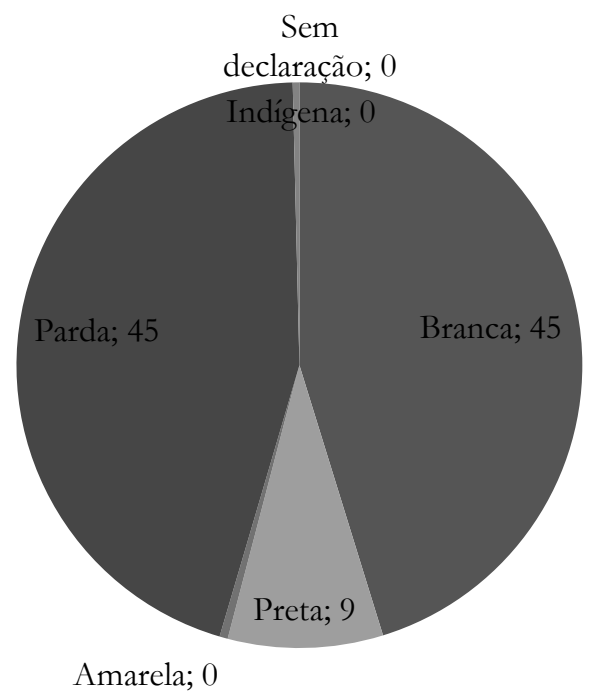

Fonte: Pesquisa Nacional por Amostra de Domicílios (PNAD) 2015 (IBGE, 2016).

${ }^{1}$ Inclusive a população sem declaração de cor ou raça.

No Gráfico 2, é possível observar a grande diferença entre brancos e negros, de acordo com os anos de estudo. Enquanto 25,5\% da população branca possui 12 anos ou mais de estudo, apenas $11,6 \%$ da população negra atinge esse nível de educação formal.

Gráfico 2 - Proporção de pessoas de 25 anos ou mais de idade com 12 anos ou mais de estudo, por Cor/Raça - 2014

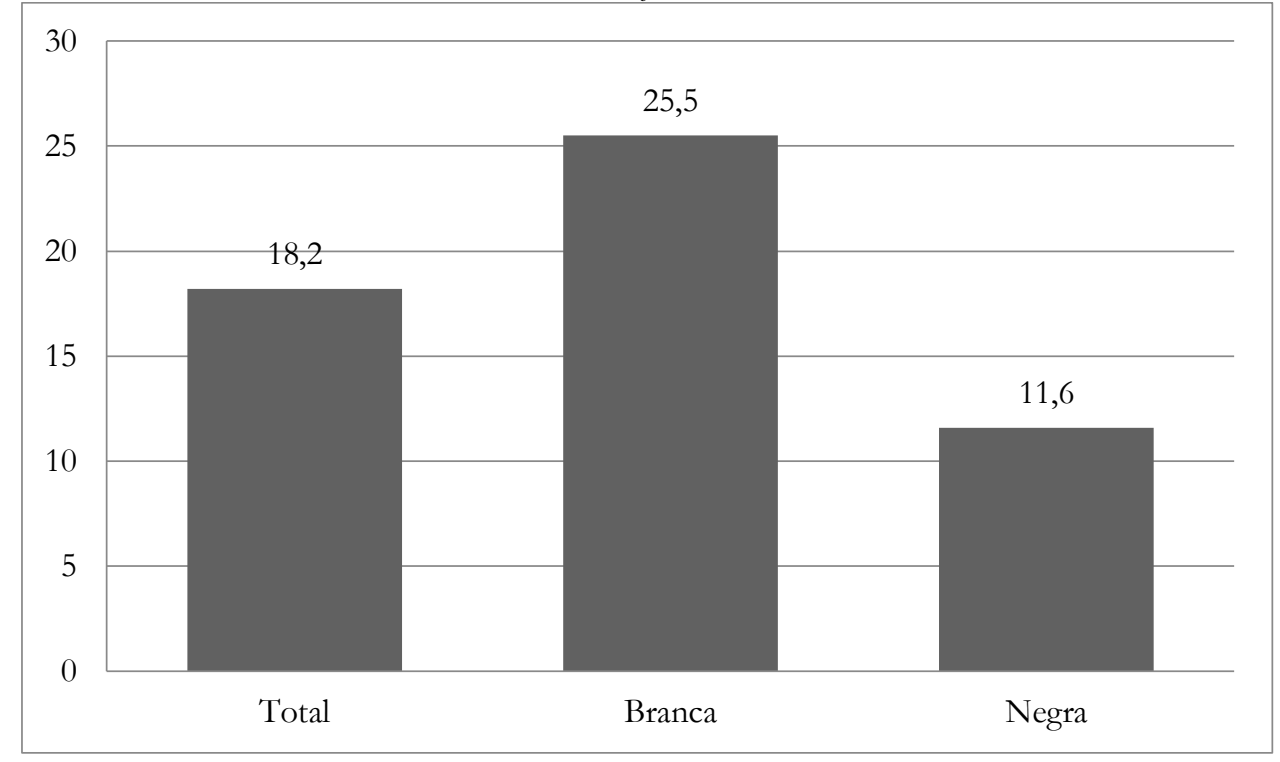

Fonte: Retrato das desigualdades de gênero e raça 1995 a 2014 (IPEA, 2014).

\footnotetext{
${ }^{2}$ A população negra abrange os autodeclarados pretos e pardos, conforme classificação adotada pelo IBGE e pelo IPEA, e consolidada na Lei n ${ }^{\circ} 12.990 / 2014$, que trata da reserva de $20 \%$ das vagas oferecidas nos concursos públicos da União aos negros. Neste artigo, será utilizado esse critério de classificação, ou seja, a referência à população negra abrangerá a população autodeclarada preta ou parda.
} 
O Gráfico 3 apresenta a diferença na taxa de frequência líquida a estabelecimento de ensino dos jovens brancos e negros. À medida que os níveis de ensino sobem, as diferenças entre brancos e negros aumentam. Assim, enquanto no ensino fundamental a diferença é praticamente inexistente, ela sobe para $21,8 \%$ no ensino médio, e para $52,6 \%$ no ensino superior.

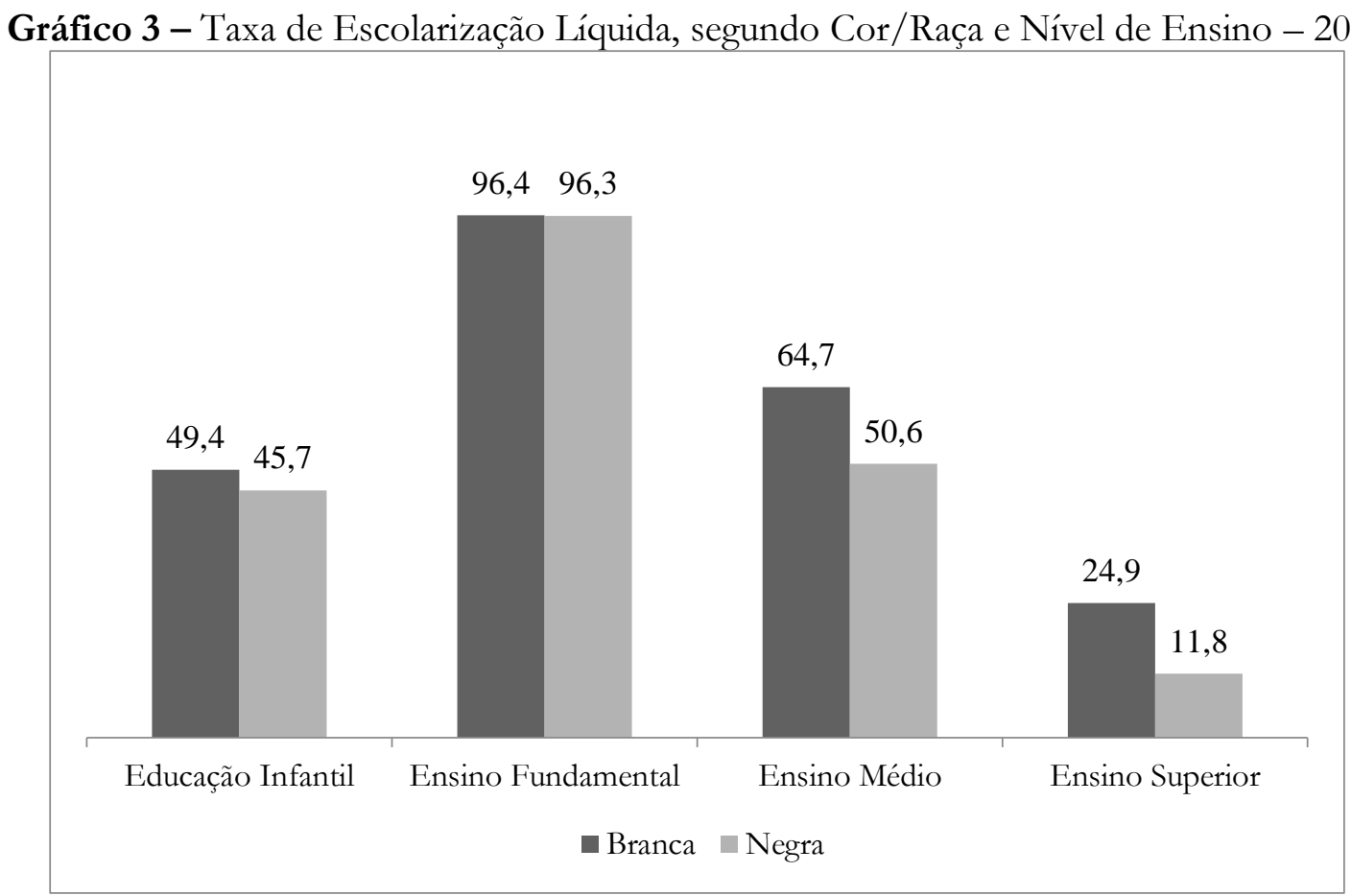

Fonte: Retrato das desigualdades de gênero e raça 1995 a 2014 (IPEA, 2014).

${ }^{1} \mathrm{Na}$ educação infantil, a faixa etária contém crianças na educação básica e no ensino fundamental. A partir de 2007, as faixas etárias da educação básica e do ensino fundamental sofrem alteração devido à Lei no 11.274/2006. A educação básica abarca crianças com até 5 anos (0 a 5 anos); já o ensino fundamental, de 6 a 14 anos, sendo que as crianças de 6 anos que não estavam cursando o ensino fundamental com 9 anos de duração foram contabilizadas no nível educação básica.

${ }^{2}$ Foram considerados adequados ao ensino superior os indivíduos que frequentam graduação, mestrado ou doutorado.

${ }^{3}$ A taxa de escolarização líquida fornece a proporção da população matriculada no nível de ensino considerado adequado conforme a faixa etária.

A educação demonstra-se fundamental para a diminuição das desigualdades sociais, econômicas e regionais, indispensáveis para um verdadeiro Estado de Direito Democrático Social. Nesse sentido, as políticas afirmativas adquirem relevância, considerando que a ideia de igualdade de oportunidades e de sua respectiva concepção de mérito não se mostram suficientes para a redução da desigualdade. Nesse sentido, Rawls (2008) discute a noção de justiça social na estrutura básica da sociedade, opondo-se à noção de mérito e destacando que a ideia de esforço individual esbarra na própria posição inicial do indivíduo, decorrente de sua condição social, familiar e de renda. Daflon, Feres Júnior e Campos (2013) afirmam que a ação afirmativa se diferencia das políticas antidiscriminatórias puramente punitivas por atuar em favor de coletividades discriminadas e indivíduos que potencialmente são discriminados, podendo ser entendida tanto como uma prevenção à discriminação quanto como uma reparação de seus efeitos; por seu turno, políticas antidiscriminatórias puramente punitivas só se preocupam em coibir comportamentos e práticas que promovam discriminação, sem, contudo, cuidar da elevação das condições de vida de grupos e indivíduos discriminados. Nesse sentido, Rawls (2008) defende que a justiça social seja alcançada pela garantia de acesso a bens primários, que permitam às pessoas buscar suas concepções de bem e desenvolver e exercer as suas faculdades morais, na medida em que constituem um mínimo denominador comum. Apesar da evolução, fica claro que a universalização do acesso ao ensino superior e a democratização do ingresso no ensino público ainda precisam trilhar um longo caminho. 
O problema central a ser investigado neste artigo é a efetividade das ações afirmativas no ensino superior, recorrendo-se a mecanismos que permitam estabelecer relações causais entre as políticas implementadas e o resultado final obtido. A pesquisa empregou métodos quantitativos, utilizando dados do Censo da Educação Superior, do Censo Demográfico, da Pesquisa Nacional por Amostra de Domicílios (PNAD), bem como de estudos do IPEA voltados à inserção do negro no ensino superior. Por meio dos dados, esta pesquisa buscou identificar o grau de êxito das políticas afirmativas implementadas no ensino superior público federal, considerando o acesso da população negra a esse nível de ensino.

Assim, foi realizada uma análise quantitativa com o intuito de mensurar os efeitos das políticas sobre o objetivo de ampliar o acesso ao ensino superior à população negra brasileira. No presente caso, a participação da população-alvo nas políticas afirmativas não é feita de forma aleatória, tendo em vista que depende de alguns fatores como localização geográfica, cor e, algumas vezes, situação econômica. Assim, optou-se pelo método quase experimental, incluindo-se grupos de controle e préteste de avaliação de resultados imediatos e de efeitos da política no público-alvo, com séries temporais de dados anteriores e posteriores à implantação.

No caso das políticas afirmativas locais, o pré-teste não foi possível, tendo em vista que os dados do Censo da Educação Superior passam a registrar a cor ou raça dos alunos apenas em 2009. Ressalva-se também que as séries temporais são reduzidas, já que a análise começou em 2009, a política nacional começou a ser implementada em 2013, e os últimos dados disponíveis são de 2015. Para a análise dos resultados, foram utilizadas análises de correlação e regressão linear múltipla.

No que se refere a avaliações de programas nacionais, não se pode desprezar a diversidade de contextos de implementação devido à grande extensão e diversidade do território brasileiro, que pode produzir resultados inteiramente diversos em diferentes unidades da Federação. Esta pesquisa buscou identificar as variáveis efetivamente relevantes para permitir a análise mais profunda dos dados, buscando outros fatores que possam causar interferência, de modo a identificar relações entre as variáveis estudadas.

\section{RASTREAMENTO DAS POLÍTICAS AFIRMATIVAS NO ENSINO SUPERIOR BRASILEIRO: MODELOS DE POLÍTICAS AFIRMATIVAS ADOTADOS}

O estado do Rio de Janeiro foi o primeiro a implementar uma política afirmativa no ensino superior brasileiro. Por meio da Lei $\mathrm{n}^{\circ} 3.524$, de 28 de dezembro de 2000, o estado em questão estabeleceu a reserva de $50 \%$ das vagas a estudantes de escolas públicas do município ou do estado. No ano seguinte, o estado do Paraná reservou três vagas por curso em suas universidades públicas estaduais para indígenas paranaenses. No mesmo ano, a Universidade Estadual do Rio Grande do Sul (UERGS) destinou $50 \%$ das vagas para estudantes carentes e 10\% para pessoas com deficiência. Porém, foi com a implantação da primeira política afirmativa racial voltada à população negra no ensino superior, por meio da Lei no 3.708, de 09 de novembro de 2001, do estado do Rio de Janeiro, que a discussão sobre reserva de vagas nas instituições de ensino superior começou a ganhar relevância nacional. Tal lei instituiu reserva de até $40 \%$ das vagas nos cursos de graduação da Universidade do Estado do Rio de Janeiro (UERJ) e da Universidade Estadual do Norte Fluminense (UENF) para estudantes negros.

Nos anos que se seguiram, diversas instituições passaram a adotar algum tipo de reserva de vagas, por meio de legislação estadual ou por meio dos conselhos universitários. Em 2003, a Universidade de Brasília aprovou resolução reservando $20 \%$ das vagas para estudantes negros. No mesmo ano, o estado do Rio de Janeiro passou a instituir nas universidades públicas estaduais a reserva de, no mínimo, $45 \%$ das vagas para ingresso nos cursos de graduação para estudantes carentes, sendo $20 \%$ para estudantes oriundos da rede pública estadual, 20\% para negros, e 5\% para pessoas com deficiência e integrantes de minorias étnicas. Foi então que a discussão nacional sobre reserva de vagas ganhou grandes proporções, tanto em relação à legitimidade dos requisitos (escola pública ou cor/raça), quanto à legalidade das políticas afirmativas.

No contexto de elaboração e implementação de políticas afirmativas no ensino superior, a maior parte das discussões girou em torno da questão "raça ou classe?". A questão da desigualdade racial é amplamente reconhecida, e existe algum grau de consenso de que são necessárias intervenções do Estado de forma a diminuir as disparidades raciais e combater o racismo. No entanto, houve grande 
discordância em relação às formas que essas políticas deveriam adotar. Daflon, Feres Júnior e Campos (2013) apontam para uma predominância da percepção de que as desigualdades de classe são mais relevantes do que as desigualdades raciais entre os articuladores das ações afirmativas para o ensino superior no nível local. De acordo com Bernardino (2002), a concepção brasileira de encarar o problema racial define como racista aquele que separa, evitando-se reconhecer o tratamento diferenciado de brasileiros em decorrência da raça, mesmo se este reconhecimento pudesse significar uma oportunidade para a correção de desigualdades. Aqui a mestiçagem foi utilizada como escudo para evitar o reconhecimento da importância da população negra na história e na vida cultural brasileira, bem como para exaltar o talvez maior mito da sociedade brasileira, o de que constituímos uma democracia racial. Assim, enquanto a reserva de vagas com critérios sociais foi vista como combate à desigualdade, muitas vezes nem percebida pelo debate público, o estabelecimento de políticas afirmativas com critérios raciais levou o tema ao centro do debate público.

Em 2004, a Confederação Nacional dos Estabelecimentos de Ensino (CONFENEN) ajuizou Ação Direta de Inconstitucionalidade (ADI 3.197) no Supremo Tribunal Federal contra a Lei no 4.151/03, do estado do Rio de Janeiro, argumentando a criação de um privilégio aos alunos carentes das escolas públicas fluminenses, prejudicando estudantes de outros estados, bem como de escolas particulares e os não negros. No mesmo ano, a CONFENEN também ajuizou a ADI 3.330 (a qual foram apensadas as ADI 3.314 e a ADI 3.379) juntamente com o partido Democratas (DEM) e a Federação Nacional dos Auditores Fiscais da Previdência Social (FENAFISP). Essa ADI questionava a medida provisória que originou o ProUni, alegando que não atendia aos requisitos de relevância e urgência para sua edição e que ofendia o princípio constitucional da isonomia entre os cidadãos brasileiros, além de desvirtuar o conceito constitucional de entidade beneficente de assistência social.

Apesar dos questionamentos judiciais e da ampla mobilização ocorrida na imprensa, em 2004 houve grande expansão das políticas afirmativas nas instituições de ensino superior do País. Assim, diversas universidades federais e estaduais implantaram políticas afirmativas locais, seja por iniciativa própria, seja por legislação estadual. Nos anos que se seguiram, mais instituições implementaram políticas afirmativas, com diversos formatos e critérios. Enquanto isso, o debate em torno dessas políticas ganhava volume na sociedade, com a tramitação no Congresso Nacional do projeto do Estatuto da Igualdade Racial e do projeto de Lei para implementação de reserva de vagas em instituições federais.

Assim, em julho de 2006, um grupo de 114 intelectuais, artistas e ativistas entregaram aos presidentes do Senado, Renan Calheiros (PMDB), e da Câmara, Aldo Rebelo (PCdoB), um manifesto contrário aos projetos. O texto pedia aos parlamentares que rejeitassem os dois projetos com o argumento de que a adoção de políticas específicas para negros poderia acirrar conflitos raciais ao dar status jurídico ao conceito de raça, além de não atacar o problema estrutural da desigualdade no País, a saber, a falta de acesso universal à educação de qualidade (DAHER FILHO et al., 2006). Como resposta a esse manifesto, outro grupo de importantes intelectuais do País lançou o Manifesto em favor da Lei de Cotas e do Estatuto da Igualdade Racial, defendendo os projetos em discussão no Congresso e afirmando que a "igualdade universal dentro da República não é um princípio vazio e sim uma meta a ser alcançada" (NASCIMENTO et al., 2009). Esse texto foi subscrito por 330 pessoas.

Em 2008, o ministro do STF, Carlos Ayres Britto, relator da matéria, levou a ADI 3.330 a julgamento e rechaçou os argumentos contra o PROUNI, julgando a ação improcedente e considerando o PROUNI constitucional. No entanto, o julgamento foi interrompido por um pedido de vista do ministro Joaquim Barbosa, e o STF só concluiu o julgamento em 2012, junto com a Arguição de Descumprimento de Preceito Fundamental (ADPF) 186 e o Recurso Extraordinário (RE) 597.285, de relatoria do ministro Ricardo Lewandowski. A ADPF 186 foi ajuizada, em 2009, pelo Partido Democratas (DEM) contra a reserva de vagas com critérios raciais adotada pela UNB, alegando que a política feria vários preceitos fundamentais da Constituição Federal, como os princípios republicano e da dignidade da pessoa humana, a igualdade e a legalidade, e o repúdio ao racismo. O partido defendia ainda que havia ofensa aos princípios da impessoalidade, da razoabilidade, da publicidade e da moralidade, e a dispositivos que estabeleciam o direito universal à educação, à igualdade nas condições de acesso ao ensino, à autonomia universitária e ao princípio meritocrático - acesso ao ensino segundo a capacidade de cada um. Já o RE 597.285 foi interposto por um estudante que não foi aprovado no vestibular da Universidade Federal do Rio Grande do Sul (UFRGS), embora tivesse alcançado pontuação 
superior a de outros candidatos. O STF julgou improcedentes as ações, por maioria de votos. Foi também em 2012 que a ADI 3.197 foi julgada prejudicada, uma vez que o relator, ministro Celso de Mello, constatou que a lei fora revogada.

Durante o período em que essas ações eram analisadas pelo STF, houve muita mobilização tanto de grupos contrários quanto favoráveis às ações afirmativas raciais, e foram enviados ao STF dois manifestos, um contrário e um favorável às políticas. O documento contrário, "113 Cidadãos Antirracistas Contra as Leis Raciais", afirma que o sistema defendido pelo Ministério da Educação tinha caráter racista e ocultava a necessidade de investimentos no ensino público de qualidade e pedia a suspensão do sistema de cotas para negros nas universidades e no programa ProUni (DAHER et al., 2008). O texto favorável defendia a manutenção de cotas como um mecanismo de inclusão social e sustentava que as ações afirmativas corrigem desigualdades raciais históricas no País (NASCIMENTO et al., 2008).

Desde o ano 2000 até hoje, diversas formas de políticas afirmativas foram implementadas no ensino superior brasileiro. De maneira geral, essas políticas ocorreram por meio de reserva de vagas (ou cota), concessão de bônus no vestibular, ou disponibilização de vagas suplementares, e visavam beneficiar grupos específicos, conforme resumido na Figura 1.

Figura 1 - Tipos de Políticas Afirmativas identificadas de 2000 a 2015

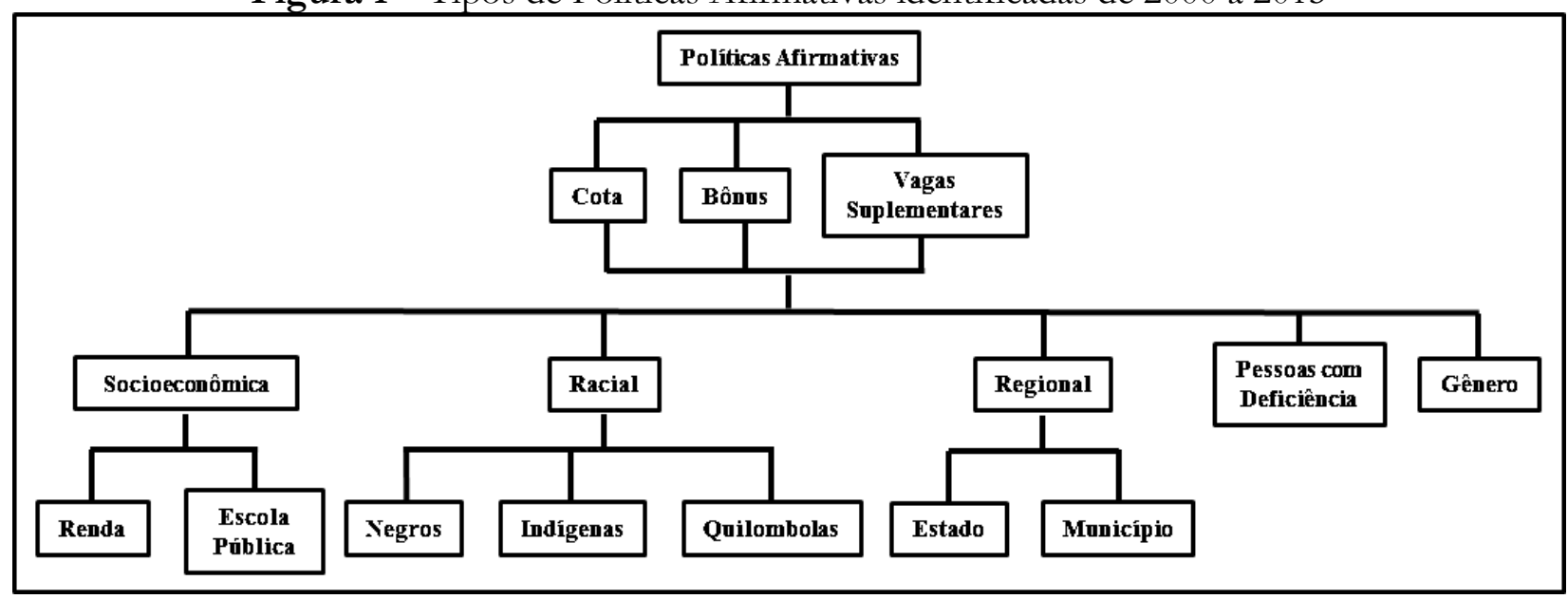

Fonte: Elaborado pela autora.

De 2000 a 2015, foram identificadas 70 políticas afirmativas implementadas por estados, municípios ou instituições de ensino. Dessas, 55 estabelecem cotas, 5 concedem bônus na pontuação do vestibular, 3 disponibilizam vagas suplementares e 7 estabelecem cotas e implementam vagas suplementares. Do total, 45 políticas possuem critérios raciais, sendo que 41 beneficiam estudantes negros. Das 41 políticas afirmativas direcionadas a estudantes negros, 31 possuem requisitos socioeconômicos. Cabe observar que a maioria das ações afirmativas raciais mencionadas adotam apenas autodeclaração para identificação da cor ou raça dos candidatos. Apenas a Universidade de Brasília, a Universidade Federal do Paraná, a Universidade Federal de Santa Catarina, a Universidade do Estado de Santa Catarina e a Universidade Estadual do Piauí exigem entrevista ou análise por comissão para validação da autodeclaração. Apenas três estados não possuíam instituições com políticas afirmativas locais; Acre, Rondônia e Ceará só passaram a ter instituições de ensino superior com políticas afirmativas a partir da implementação da política nacional, em 2013. Já políticas afirmativas direcionadas à população negra estavam ausentes em 13 estados, antes da implementação da política afirmativa nacional.

As instituições pertencentes aos sistemas estaduais de educação possuem regulamentações próprias e permanecem com diferentes desenhos de políticas afirmativas. No entanto, as instituições federais de ensino, que até 2012 definiam se e como implantar ações afirmativas, passaram a ser obrigadas a adotar a política afirmativa nacional a partir de 2013. De acordo com a regra nacional, as instituições devem reservar, no mínimo, $50 \%$ de suas vagas para estudantes que tenham cursado integralmente o ensino médio em escolas públicas, distribuídas entre autodeclarados pretos, pardos e indígenas, conforme 
composição étnica da respectiva Unidade da Federação, sendo que 50\% são reservadas aos estudantes oriundos de famílias com renda igual ou inferior a 1,5 salário mínimo per capita. O projeto de lei que estabelece o sistema de cotas raciais e sociais nas instituições federais públicas de educação superior e escolas técnicas estava parado desde 2008, quando foi aprovado pela Câmara e pela Comissão de Constituição e Justiça (CCJ) do Senado, em junho de 2012. A votação no Senado ocorreu depois que o STF, em abril daquele ano, decidiu que o sistema de cotas raciais em universidades é constitucional. Assim, a Lei $\mathrm{n}^{\mathrm{o}}$ 12.711, de 29 de agosto de 2012, e o Decreto $\mathrm{n}^{\circ}$ 7.824, de 11 de outubro de 2012, uniformizaram a política afirmativa para as instituições federais de ensino superior, conforme Figura 2.

Figura 2 - Lei no 12.711 , de 29 de agosto de 2012

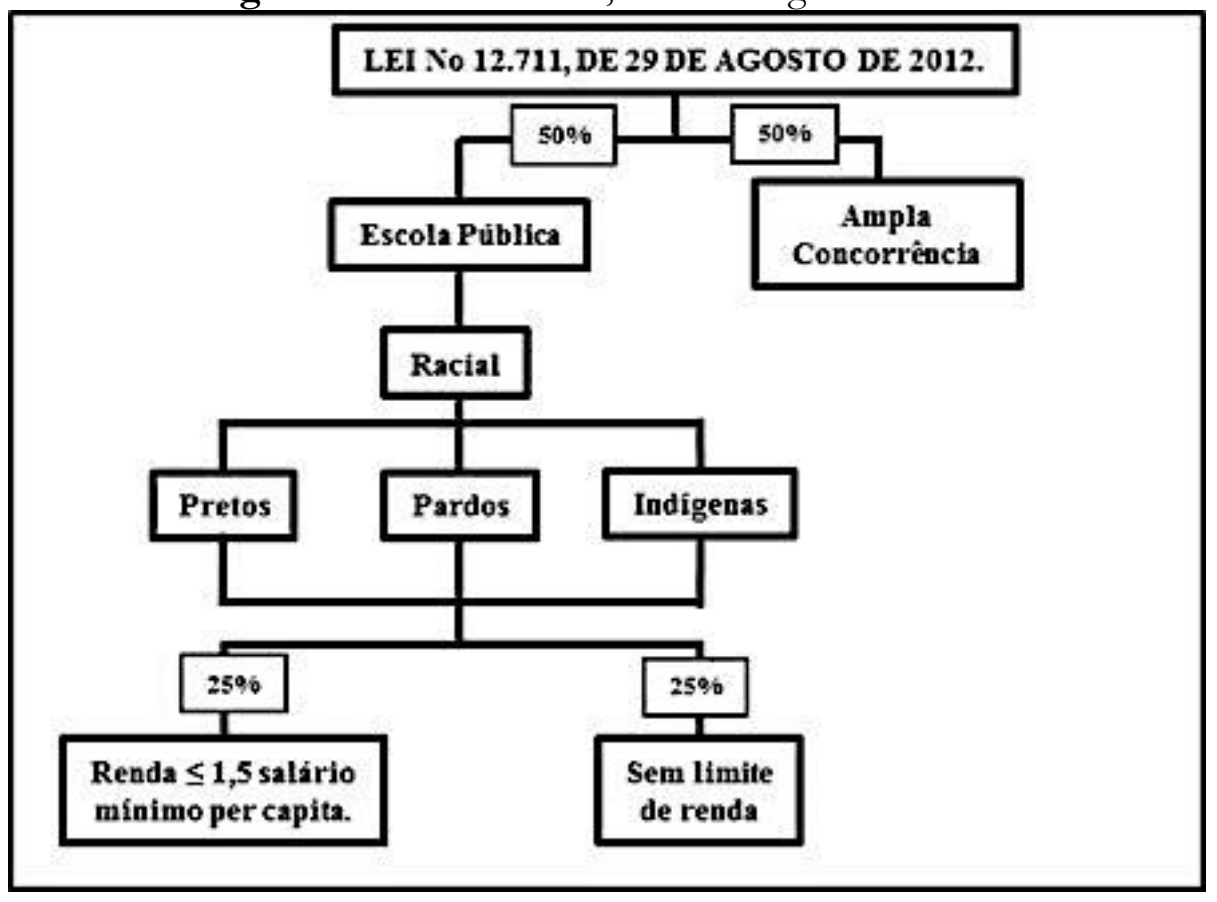

Fonte: Elaborado pela autora.

\section{POLÍTICAS AFIRMATIVAS NO ENSINO SUPERIOR: A EVOLUÇÃO DOS DADOS}

Nessa etapa da análise quantitativa, o intuito foi identificar alterações no acesso ao ensino superior para a população negra, bem como algum tipo de interação entre as variáveis. Assim, foram identificadas variáveis para a elaboração dos modelos de regressão linear múltipla, como se verá a seguir. Tendo em vista que menos de 6\% dos alunos nas Instituições Federais de Ensino Superior frequentam cursos superiores tecnológicos, este estudo optou por focar apenas os cursos de Bacharelados e Licenciaturas.

Foram utilizados dados do Censo da Educação Superior, que inclui (ou deveria incluir) a informação sobre a cor ou raça de cada um dos estudantes, distribuída entre branca, negra, amarela, indígena ou sem informação. Cabe observar que um alto percentual de sem informação inviabiliza a análise dos efeitos das políticas afirmativas no acesso ao ensino superior, tendo em vista que os aumentos percentuais de negros poderiam representar apenas uma melhoria na coleta de respostas. Nesse sentido, conforme os dados do Censo da Educação Superior de 2009 a 2015 (INEP, 2016a, 2016b, 2016c, 2016d, 2016e, 2016f, 2016g), houve uma redução de 53,4\% de sem informação, a partir de 2011. Assim, considerando esses dados, bem como o objetivo desta pesquisa, para a análise quantitativa foram selecionadas as instituições federais que, de 2009 a 2015, possuíam pelo menos $50 \%$ de resposta à questão cor ou raça dos alunos. Optou-se pelas instituições federais porque estas passaram por uma mudança uniforme no desenho de suas políticas por meio da Lei no 12.711, de 29 de agosto de 2012. Assim, foi possível avaliar a alteração no acesso de negros tanto em instituições que até 2012 não possuíam qualquer política afirmativa, quanto em instituições que até então possuíam diversos formatos de ações afirmativas 
locais, permitindo uma análise abrangente de resultados de diferentes políticas. Além disso, com essa escolha foram abrangidas as cinco regiões do País. Assim, foram analisados os mesmos contextos de implantação em dois momentos diferentes e com desenhos diversos, permitindo uma apreensão mais rica dos resultados observados. Ademais, tendo o histórico dessas instituições, é possível analisar com mais profundidade as diferenças de resultados da Lei nº 12.711/2012. Assim, das 107 instituições federais de Ensino Superior que ofertam Bacharelados e/ou Licenciaturas, foram selecionadas 30.

Para diminuir as probabilidades de erros nas análises, algumas instituições que haviam sido selecionadas de acordo com o critério apresentado foram excluídas da análise, tendo em vista altos percentuais de sem informação de cor ou raça dos alunos ingressantes, distorção nos dados de cor ou raça dos alunos ou identificação de instituições voltadas a públicos específicos e que, portanto, poderiam corromper os resultados. Assim, das 30 instituições previamente selecionadas, foram mantidas apenas 21.

Das 21 instituições analisadas, 19 apresentaram associação positiva de ingressantes negros e a política afirmativa nacional, em diferentes graus, de acordo com o Quadro 1. Isso quer dizer que o aumento na quantidade de ingressantes negros está associado, ao menos em parte, à implementação da política nacional. Uma instituição apresentou independência entre as variáveis, ou seja, a variação no percentual de ingressantes negros não possui associação com a implementação da política, e uma apresentou associação negativa, mas em valor insignificante, o que indicaria que a implementação da política afetou negativamente o percentual de ingressantes negros. Das seis instituições em que foi possível analisar a associação entre ingressantes negros e a política afirmativa local, apenas uma apresentou alta associação positiva, ou seja, a implementação da política local está associada ao aumento significativo no percentual de ingressantes negros.

Quadro 1 - Instituições selecionadas para Análise Quantitativa e respectivas políticas afirmativas locais

\begin{tabular}{|c|c|c|c|c|c|c|c|c|c|}
\hline \multirow[b]{3}{*}{ UF } & \multirow[b]{3}{*}{ Instituição } & \multicolumn{8}{|c|}{ Qui-Quadrado ou Fisher: Resíduos Ajustados } \\
\hline & & \multicolumn{4}{|c|}{ Política Nacional } & \multicolumn{4}{|c|}{ Política Local } \\
\hline & & Brancos & Negros & $\begin{array}{l}\text { Ingressa } \\
\text { ntes } \\
\text { Brancos }\end{array}$ & $\begin{array}{l}\text { Ingressa } \\
\text { ntes } \\
\text { Negros }\end{array}$ & Brancos & Negros & $\begin{array}{l}\text { Ingressa } \\
\text { ntes } \\
\text { Brancos }\end{array}$ & $\begin{array}{c}\text { Ingressa } \\
\text { ntes } \\
\text { Negros }\end{array}$ \\
\hline GO & $\begin{array}{l}\text { Instituto Federal de } \\
\text { Educação, Ciência e } \\
\text { Tecnologia Goiano }\end{array}$ & $-9,6$ & 4,4 & $-5,9$ & 7,1 & & & & \\
\hline MT & $\begin{array}{c}\text { Universidade } \\
\text { Federal de Mato } \\
\text { Grosso } \\
\end{array}$ & 7 & 52,6 & $-1,8$ & 35,4 & & & & \\
\hline $\mathrm{CE}$ & $\begin{array}{l}\text { Instituto Federal de } \\
\text { Educação, Ciência e } \\
\text { Tecnologia do Ceará }\end{array}$ & 4,6 & 21,1 & 5,6 & 23,1 & & & & \\
\hline PB & $\begin{array}{c}\text { Instituto Federal de } \\
\text { Educação, Ciência e } \\
\text { Tecnologia da } \\
\text { Paraíba }\end{array}$ &,- 14 & 4,2 & $-3,2$ & 8,9 & 1,6 & 0 & $-0,1$ & 4,4 \\
\hline PE & $\begin{array}{c}\text { Instituto Federal de } \\
\text { Educação, Ciência e } \\
\text { Tecnologia do } \\
\text { Sertão } \\
\text { Pernambucano } \\
\end{array}$ & 0,4 & 6,6 & $-1,4$ & 8,5 & 1,5 & 2,1 & 0,4 & 3,1 \\
\hline SE & $\begin{array}{c}\text { Universidade } \\
\text { Federal de Sergipe }\end{array}$ & $-17,4$ & 37,7 & -9 & 10,8 & & & & \\
\hline $\mathrm{AM}$ & $\begin{array}{c}\text { Instituto Federal de } \\
\text { Educação, Ciência e } \\
\text { Tecnologia do } \\
\text { Amazonas }\end{array}$ & $-1,2$ & 9,7 & & & 1,1 & 7,7 & & \\
\hline PA & $\begin{array}{l}\text { Instituto Federal de } \\
\text { Educação, Ciência e } \\
\text { Tecnologia do Pará }\end{array}$ & $-4,9$ & 7,7 & $-5,1$ & 8,7 & 2,5 & -0.4 & 4,5 & 2,5 \\
\hline
\end{tabular}




\begin{tabular}{|c|c|c|c|c|c|c|c|c|c|}
\hline TO & $\begin{array}{c}\text { Universidade } \\
\text { Federal do } \\
\text { Tocantins } \\
\end{array}$ & 14,9 & 35,1 & $-3,7$ & 33,2 & & & & \\
\hline TO & $\begin{array}{c}\text { Instituto Federal de } \\
\text { Educação, Ciência e } \\
\text { Tecnologia do } \\
\text { Tocantins }\end{array}$ & $-0,2$ & 6,4 & 0,7 & 9,7 & $-0,3$ & 0,4 & $-0,4$ & 0,6 \\
\hline $\mathrm{ES}$ & $\begin{array}{c}\text { Instituto Federal de } \\
\text { Educação, Ciência e } \\
\text { Tecnologia do } \\
\text { Espírito Santo }\end{array}$ & 6,1 & 13,5 & 0,2 & 11,5 & $-2,3$ & 0,5 & $-4,7$ & 0,4 \\
\hline $\mathrm{MG}$ & $\begin{array}{c}\text { Universidade } \\
\text { Federal de Ouro } \\
\text { Preto }\end{array}$ & $-13,5$ & 19,8 & $-11,5$ & 8,2 & & & & \\
\hline RJ & $\begin{array}{c}\text { Instituto Federal de } \\
\text { Educação, Ciência e } \\
\text { Tecnologia } \\
\text { Fluminense } \\
\end{array}$ & 9 & 10,9 & 4,8 & 10,5 & & & & \\
\hline RJ & $\begin{array}{c}\text { Universidade } \\
\text { Federal do Rio de } \\
\text { Janeiro }\end{array}$ & $-51,4$ & 36,5 & $-13,7$ & 34,8 & $-54,9$ & 19,1 & $-9,6$ & 26,8 \\
\hline $\mathrm{SP}$ & $\begin{array}{c}\text { Universidade } \\
\text { Federal de São } \\
\text { Carlos } \\
\end{array}$ & 28,6 & 33,4 & 13,3 & 19 & & & & \\
\hline $\mathrm{RS}$ & $\begin{array}{c}\text { Universidade } \\
\text { Federal do Pampa }\end{array}$ & 7,6 & 13,9 & 23 & 8 & & & & \\
\hline RS & $\begin{array}{c}\text { Instituto Federal de } \\
\text { Educação, Ciência e } \\
\text { Tecnologia do Rio } \\
\text { Grande do Sul }\end{array}$ & 6,3 & 4,9 & 12,4 & 5,9 & & & & \\
\hline RS & $\begin{array}{c}\text { Instituto Federal de } \\
\text { Educação, Ciência e } \\
\text { Tecnologia } \\
\text { Farroupilha }\end{array}$ & $-1,7$ & 5,4 & $-3,4$ & 6,2 & & & & \\
\hline RS & $\begin{array}{c}\text { Universidade } \\
\text { Federal de Santa } \\
\text { Maria } \\
\end{array}$ & 3,4 & 24,5 & 1,8 & 10,2 & & & & \\
\hline SC & $\begin{array}{l}\text { Instituto Federal de } \\
\text { Educação, Ciência e } \\
\text { Tecnologia de Santa } \\
\text { Catarina }\end{array}$ & 17,1 & 1 & 14,3 & $-0,2$ & & & & \\
\hline SC & $\begin{array}{c}\text { Universidade } \\
\text { Federal de Santa } \\
\text { Catarina }\end{array}$ & $-1,8$ & 12,5 & $-0,7$ & 6 & & & & \\
\hline
\end{tabular}

Fonte: Censo da Educação Superior 2009 a 2015 (INEP, 2016a, 2016b, 2016c, 2016d, 2016e, 2016f, 2016g).

${ }^{1}$ Calculado com o software IBM SPSS Statistics.

O Gráfico 4 mostra que, nas instituições selecionadas que possuem políticas afirmativas para escola pública, houve um aumento no percentual de ingressantes negros, sinalizando um impulso maior a partir de 2013, com a implementação da política afirmativa nacional. Nas instituições com políticas afirmativas para escola pública e para negros, observa-se uma oscilação maior, um aumento no percentual de ingressantes negros de 2009 a 2011, uma estabilização em 2012, uma pequena queda em 2013, um aumento em 2014 e uma nova queda em 2015. Já nas instituições sem políticas afirmativas, nota-se um aumento de 2009 a 2012 e um aumento bem maior a partir de 2013, com a implementação da política afirmativa nacional. 
Gráfico 4-Comparativo do percentual de ingressantes por cor ou raça e política afirmativa

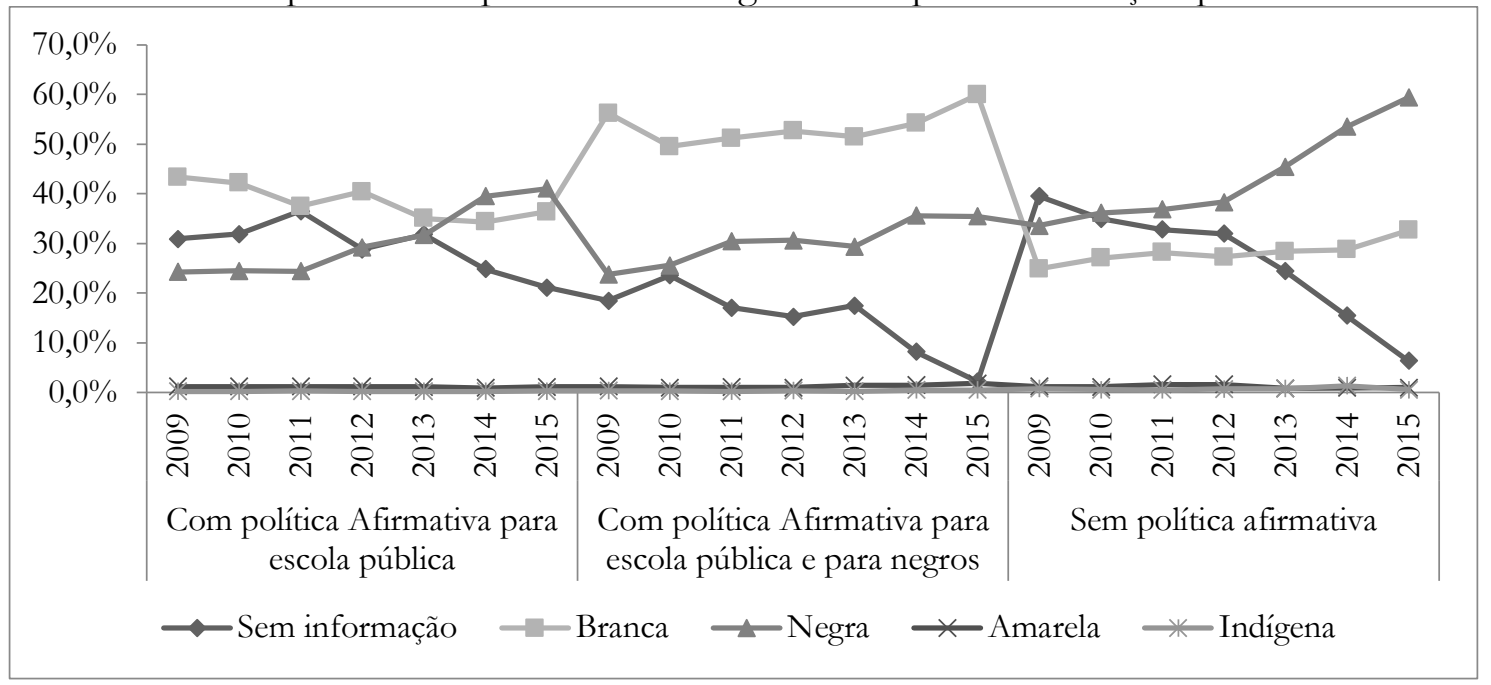

Fonte: Censo da Educação Superior 2009 a 2015 (INEP, 2016a, 2016b, 2016c, 2016d, 2016e, 2016f, 2016g).

O teste do Qui-quadrado para análise de interação entre a cor/raça dos ingressantes e o ano, por grupos de políticas afirmativas, $\operatorname{com} \mathrm{p}=0,000$, rejeitou hipótese de independência entre as variáveis, significando que a implementação de políticas afirmativas tem relação com a variaçãos nos percentais de cor/raça dos ingressantes. O Gráfico 5 apresenta a análise dos resíduos ajustados. É possível observar que ingressantes negros possuem associação negativa até o ano de 2012 no grupo de intituições que implantaram políticas afirmativas locais para escola pública. A partir de 2013, esse grupo passa a apresentar associação positiva. A situação repete-se no grupo de instituições que não implantaram políticas afirmativas locais. Já no grupo de instituições que implantaram políticas afirmativas locais para escola pública e para negros, a associação passa a ser positiva em 2011, ou seja, antes da implementação da política afirmativa nacional.

Gráfico 5 - Comparativo dos resíduos ajustados por cor ou raça e política afirmativa

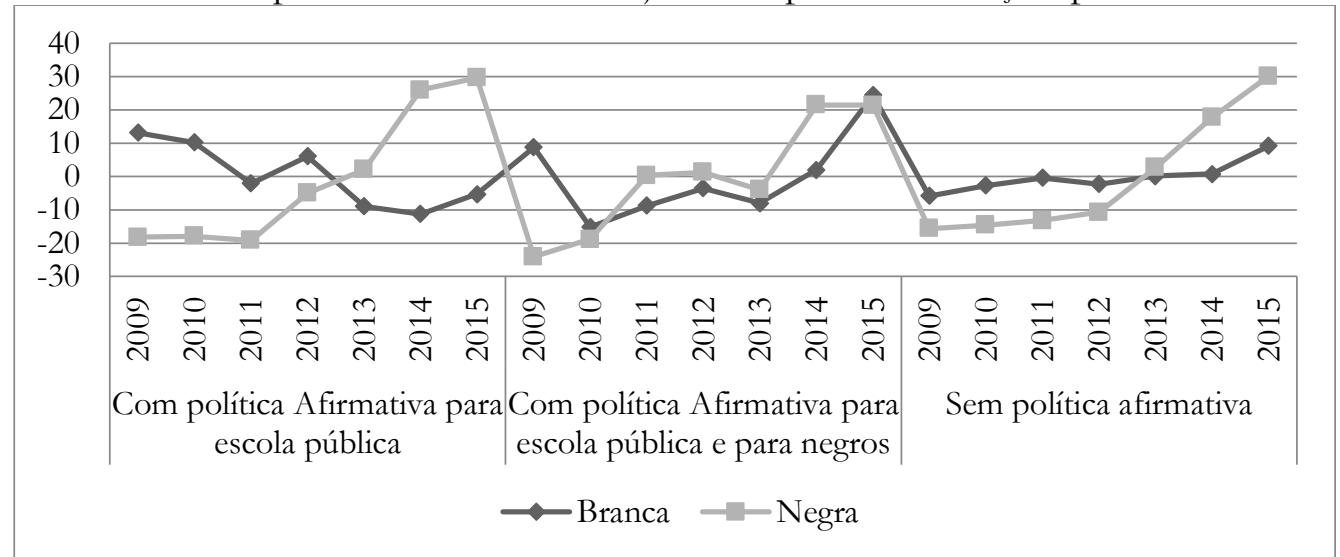

Fonte: Censo da Educação Superior 2009 a 2015 (INEP, 2016a, 2016b, 2016c, 2016d, 2016e, 2016f, 2016g).

${ }^{1}$ Calculado com o software IBM SPSS Statistics.

Uma das hipóteses levantadas pela pesquisa é que os ingressantes beneficiados pelas reservas de vagas se concentrariam nos cursos com notas de corte mais baixas. O teste do Qui-quadrado para análise de interação entre a cor/raça dos ingressantes e o curso, com p $=0,000$, rejeitou hipótese de independência entre as variáveis e mostrou que os ingressantes negros realmente se concentram nos cursos com notas de corte mais baixas e menos disputados.

A Tabela 1 apresenta a análise dos resíduos ajustados de alguns cursos. É possível observar que ingressantes negros possuem associação negativa mais forte com os cursos de Engenharia $(-28,1)$, Relações Internacionais (-12,6), Comunicação Social (-11,8), Farmácia (-10,8), Direito (-10,6). Já a 
associação positiva mais forte dos ingressantes negros ocorre nos cursos de Educação do Campo (17,3), Química (19,0), Matemática (20,8), Geografia $(22,5)$, Física $(25,1)$.

Tabela 1 - Correlação rô de Spearman para variável dependente \% ingressantes negros

\begin{tabular}{|c|c|c|}
\hline \multirow{2}{*}{ Curso } & \multicolumn{2}{|c|}{ Resíduos ajustados } \\
\hline & Branca & Negra \\
\hline Engenharia & 35,5 & $-28,1$ \\
\hline Relações Internacionais & 7,3 & $-12,6$ \\
\hline Comunicação Social & 12,2 & $-11,8$ \\
\hline Farmácia & 7,3 & $-10,8$ \\
\hline Direito & 0,6 & $-10,6$ \\
\hline Arquitetura e Urbanismo & 4,8 & -10 \\
\hline Design & 11,2 & $-9,8$ \\
\hline Agronomia & 14,6 & $-9,3$ \\
\hline Psicologia & 11 & $-9,3$ \\
\hline Medicina & 7 & $-8,4$ \\
\hline Odontologia & 7,6 & $-8,3$ \\
\hline Ciência Política & 8,6 & $-8,2$ \\
\hline Economia & 9,3 & $-6,5$ \\
\hline Administração & 7,2 & $-6,2$ \\
\hline Ciências Sociais & $-8,3$ & $-5,6$ \\
\hline Fisioterapia & -2 & -4 \\
\hline Medicina Veterinária & 7,6 & $-2,7$ \\
\hline Biologia & $-13,4$ & 2,1 \\
\hline Fonoaudiologia & 0,4 & 2,1 \\
\hline Ciências Contábeis & $-0,7$ & 3,2 \\
\hline Enfermagem & $-5,5$ & 4 \\
\hline Pedagogia & $-2,3$ & 4,8 \\
\hline Educação Física & $-14,2$ & 5,4 \\
\hline Filosofia & $-2,2$ & 5,7 \\
\hline Estatística & $-2,4$ & 6,6 \\
\hline Secretariado Executivo & 0,5 & 7,2 \\
\hline Turismo & $-4,9$ & 7,9 \\
\hline Saúde Coletiva & -10 & 9,3 \\
\hline História & $-15,6$ & 9,4 \\
\hline Ciência da Computação & -6 & 9,8 \\
\hline Sistemas de Informação & 0,2 & 11,3 \\
\hline Serviço Social & $-9,6$ & 15,3 \\
\hline Letras & $-17,5$ & 16,9 \\
\hline Educação do Campo & $-6,5$ & 17,3 \\
\hline Química & $-16,3$ & 19 \\
\hline Matemática & $-18,6$ & 20,8 \\
\hline Geografia & $-19,8$ & 22,5 \\
\hline Física & $-18,7$ & 25,1 \\
\hline
\end{tabular}

Fonte: Censo da Educação Superior 2009 a 2015 (INEP, 2016a, 2016b, 2016c, 2016d, 2016e, 2016f, 2016g).

${ }^{1}$ Calculado com o software IBM SPSS Statistics.

O problema dessa correlação é a diminuição do potencial de redução de desigualdade entre brancos e negros, tendo em vista que as carreiras com maior associação com ingressantes negros são também as profissões com remunerações mais baixas. Enquanto isso, as carreiras com maior associação com ingressantes brancos são as que oferecem remunerações mais altas e mais prestígio no mercado de trabalho.

\section{POLÍTICAS AFIRMATIVAS NO ENSINO SUPERIOR: AVALIAÇÃO DA EFETIVIDADE}

$\mathrm{Na}$ parte final deste estudo, foram realizadas análises de regressão múltipla para uma avaliação da efetividade das políticas afirmativas locais e da política afirmativa nacional. Cabe observar que a variável política afirmativa local não identifica o desenho específico de cada instituição, mas simplesmente a existência ou não desse tipo de política. O mesmo critério foi utilizado para a variável 
política afirmativa nacional, que tampouco identifica o percentual de vagas ofertadas por cada instituição. Tanto a variável política afirmativa local quanto a política afirmativa nacional foram categorizadas como variáveis dummy. A análise não fica prejudicada com essas opções metodológicas, uma vez que também são analisados os percentuais de vagas reservadas, com dados individualizados por cada instituição. Para a análise geral da associação entre o perfil dos alunos das instituições e as políticas afirmativas locais e nacional, foram elaborados modelos de regressão linear múltipla e tabelas de correlação de Spearman.

Antes de elaborar os modelos de regressão, foram analisadas as correlações entre a variável $\%$ de ingressantes negros e as possíveis variáveis explicativas, conforme Tabela 2 . A Correlação rô de Spearman mostra interação negativa com a política afirmativa local e positiva com a política afirmativa nacional. Também são inversos os efeitos dos percentuais de brancos (negativo) e negros (positivo) na instituição e no Estado. Por óbvio, o percentual de ingressantes brancos afeta negativamente o percentual de ingressantes negros. O percentual de vagas reservadas para escola pública interage mais negativamente do que interage positivamente o percentual de vagas reservadas para negros. Por outro lado, a existência de política afirmativa para negros afeta positivamente, mas pouco, o percentual de ingressantes, enquanto não é significativa a interação com a política afirmativa para escola pública.

Tabela 2 - Correlação rô de Spearman para variável dependente \% ingressantes negros

\begin{tabular}{|c|c|c|}
\hline Variáveis & rô de Spearman & $\%$ Ingressantes negros \\
\hline \multirow{3}{*}{ Política afirmativa local } & Coeficiente de Correlação &,$- 228^{1}$ \\
\hline & Sig. (bilateral) & ,005 \\
\hline & $\mathrm{N}$ & 147 \\
\hline \multirow{3}{*}{ Política afirmativa nacional } & Coeficiente de Correlação & $258^{1}$ \\
\hline & Sig. (bilateral) & ,002 \\
\hline & $\mathrm{N}$ & 147 \\
\hline \multirow{3}{*}{$\%$ Brancos } & Coeficiente de Correlação &,$- 828^{1}$ \\
\hline & Sig. (bilateral) & 0 \\
\hline & $\mathrm{N}$ & 147 \\
\hline \multirow{3}{*}{$\%$ Negros } & Coeficiente de Correlação & ,976 \\
\hline & Sig. (bilateral) & 0 \\
\hline & $\mathrm{N}$ & 147 \\
\hline \multirow{3}{*}{$\%$ Brancos Ingressantes } & Coeficiente de Correlação &,$- 815^{1}$ \\
\hline & Sig. (bilateral) & 0 \\
\hline & $\mathrm{N}$ & 147 \\
\hline \multirow{3}{*}{$\%$ Brancos UF } & Coeficiente de Correlação &,$- 890^{1}$ \\
\hline & Sig. (bilateral) & 0 \\
\hline & $\mathrm{N}$ & 147 \\
\hline \multirow{3}{*}{$\%$ Negros UF } & Coeficiente de Correlação &, $891^{1}$ \\
\hline & Sig. (bilateral) & 0 \\
\hline & $\mathrm{N}$ & 147 \\
\hline \multirow{3}{*}{$\begin{array}{c}\% \text { Vagas reservadas para escola } \\
\text { pública }\end{array}$} & Coeficiente de Correlação &,$- 347^{1}$ \\
\hline & Sig. (bilateral) & 0 \\
\hline & $\mathrm{N}$ & 140 \\
\hline \multirow{3}{*}{$\%$ Vagas reservadas para negros } & Coeficiente de Correlação & $246^{1}$ \\
\hline & Sig. (bilateral) & ,003 \\
\hline & $\mathrm{N}$ & 147 \\
\hline \multirow{3}{*}{ Política afirmativa para negros } & Coeficiente de Correlação &,- 062 \\
\hline & Sig. (bilateral) &, 456 \\
\hline & $\mathrm{N}$ & 147 \\
\hline \multirow{3}{*}{$\begin{array}{l}\text { Política afirmativa para escola } \\
\text { pública }\end{array}$} & Coeficiente de Correlação & 021 \\
\hline & Sig. (bilateral) & 0,8 \\
\hline & $\mathrm{N}$ & 147 \\
\hline
\end{tabular}




\section{Fontes:}

Censo da Educação Superior 2009 a 2015 (INEP, 2016a, 2016b, 2016c, 2016d, 2016e, 2016f, 2016g).

Pesquisa Nacional por Amostra de Domicílios (PNAD) 2009 e 2011 a 2015 (IBGE, 2010, 2012, 2013, 2015ª, 2015b, 2016).

Censo Demográfico 2010 (IBGE, 2011).

${ }^{1}$ A correlação é significativa no nível 0,01 (bilateral).

${ }^{2}$ A correlação é significativa no nível 0,05 (bilateral).

${ }^{3}$ Calculado com o software IBM SPSS Statistics.

Assim, foram elaborados três modelos visando mensurar a relação entre a variável dependente $\%$ de ingressantes negros, e as variáveis independentes, conforme Quadro 2. Para elaboração dos modelos, partiu-se do princípio de que o percentual de negros no Estado influencia o percentual de negros na instituição. A hipótese foi reforçada pelo alto coeficiente de correção de Spearman já apresentado na Tabela 2. Portanto, essa variável foi inserida nos três modelos. Já as outras variáveis inseridas em cada modelo buscam mensurar se e quanto a variável dependente é afetada: 1) pela existência de políticas afirmativas (locais e nacional); 2) pelos tipos de políticas afirmativas (para negros e para escola pública); e/ou 3) pelos percentuais de vagas reservadas (para negros e para escola pública).

Quadro 2 - Modelos para análise de Regressão Múltipla

\begin{tabular}{|c|c|c|}
\hline Modelo & $\begin{array}{c}\text { Variável } \\
\text { Dependente }\end{array}$ & Variáveis independentes \\
\hline 1 & \multirow{3}{*}{$\begin{array}{c}\% \text { de } \\
\text { ingressantes } \\
\text { negros }\end{array}$} & \% Negros UF, Política Afirmativa Nacional, Política Afirmativa Local \\
\hline 2 & & \% Negros UF, PANegros, PAEscolaPública \\
\hline 3 & & \% Negros UF, \% Vagas Reservadas Escola Pública, \% Vagas Reservadas Negros \\
\hline
\end{tabular}

Fonte: Elaborado pela autora.

Modelo 1 - Variável Dependente: \% de ingressantes negros / Variáveis independentes: \% Negros UF, Política Afirmativa Nacional, Política Afirmativa Local.

A indicação do valor de R2 mostra que as três variáveis, no seu conjunto, explicam 82,8\% do percentual de ingressantes negros, valor muito próximo ao R2 ajustado (Tabela 3).

Tabela 3 - Sumarização do modelo 1

\begin{tabular}{c|c|c|c|c} 
Modelo & $\mathrm{R}$ & R quadrado & R quadrado ajustado & Erro padrão da estimativa \\
\hline 1 &, $910^{1}$ &, 828 &, 824 & $9,0992 \%$ \\
\hline
\end{tabular}

\section{Fontes:}

Censo da Educação Superior 2009 a 2015 (INEP, 2016a, 2016b, 2016c, 2016d, 2016e, 2016f, 2016g).

Pesquisa Nacional por Amostra de Domicílios (PNAD) 2009 e 2011 a 2015 (IBGE, 2010, 2012, 2013, 2015 , 2015b, 2016).

Censo Demográfico 2010 (IBGE, 2011).

${ }^{1}$ Preditores: (Constante), \% Negros UF, Política Afirmativa Nacional, Política Afirmativa Local.

2 Calculado com o software IBM SPSS Statistics.

A regressão mostra-se significativa com $\mathrm{F}(3,143)=229,3$ e $\mathrm{p}=0,000$ e indica que as três variáveis contribuem para a explicação de uma fração significativa da variação dos percentuais de ingressantes negros, conforme Quadro 3.

Quadro 3 - ANOVA do Modelo 1

\begin{tabular}{|c|c|c|c|c|c|c|}
\hline \multicolumn{2}{|c|}{ Modelo } & Soma dos Quadrados & gl & Quadrado Médio & F & Sig. \\
\hline \multirow{3}{*}{1} & Regressão & 56946,654 & 3 & 18982,218 & 229,264 &, $000^{\mathrm{b}}$ \\
\cline { 2 - 7 } & Resíduo & 11839,866 & 143 & 82,796 & & \\
\cline { 2 - 8 } & Total & 68786,520 & 146 & & & \\
\hline
\end{tabular}


Fontes:

Censo da Educação Superior 2009 a 2015 (INEP, 2016a, 2016b, 2016c, 2016d, 2016e, 2016f, 2016g).

Pesquisa Nacional por Amostra de Domicílios (PNAD) 2009 e 2011 a 2015 (IBGE, 2010, 2012, 2013, 2015a , 2015b, 2016).

Censo Demográfico 2010 (IBGE, 2011).

${ }^{1}$ Calculado com o software IBM SPSS Statistics.

O efeito de todos os preditores é significativo, embora o efeito do percentual de negros no estado seja bem superior, já que $\beta=0,885, \mathrm{t}=25,166, \mathrm{p}=0,000$; enquanto, para política nacional, $\beta=$ $0,277, \mathrm{t}=6,185, \mathrm{p}=0,000$ e, para polítical local, $\beta=0,102, \mathrm{t}=2,255, \mathrm{p}=0,026$, de acordo com Quadro 4.

Quadro 4 - Coeficientes do Modelo 1

\begin{tabular}{|c|c|c|c|c|c|c|c|}
\hline \multirow{2}{*}{ Variáveis } & \multicolumn{2}{|c|}{$\begin{array}{c}\text { Coeficientes não } \\
\text { padronizados }\end{array}$} & \multirow{2}{*}{$\begin{array}{c}\begin{array}{c}\text { Coeficientes } \\
\text { padronizados }\end{array} \\
\text { Beta }\end{array}$} & \multirow{2}{*}{$\mathrm{t}$} & \multirow{2}{*}{ Sig. } & \multicolumn{2}{|c|}{ Estatísticas de colinearidade } \\
\hline & B & $\begin{array}{l}\text { Erro } \\
\text { Padrão }\end{array}$ & & & & Tolerância & VIF \\
\hline (Constante) & $-13,510$ & 2,426 & & $-5,570$ &, 000 & & \\
\hline $\begin{array}{l}\text { Política Afirmativa } \\
\text { Local }\end{array}$ & 4,646 & 2,060 & ,102 & 2,255 & ,026 &, 586 & 1,707 \\
\hline $\begin{array}{c}\text { Política Afirmativa } \\
\text { Nacional }\end{array}$ & 12,125 & 1,960 & ,277 & 6,185 &, 000 & ,598 & 1,671 \\
\hline$\%$ Negros UF & ,836 & ,033 & ,885 & 25,166 &, 000 & ,972 & 1,028 \\
\hline
\end{tabular}

\section{Fontes:}

Censo da Educação Superior 2009 a 2015 (INEP, 2016a, 2016b, 2016c, 2016d, 2016e, 2016f, 2016g).

Pesquisa Nacional por Amostra de Domicílios (PNAD) 2009 e 2011 a 2015 (IBGE, 2010, 2012, 2013, 2015a, 2015b, 2016).

Censo Demográfico 2010 (IBGE, 2011).

${ }^{1}$ Calculado com o software IBM SPSS Statistics.

Os valores de Tolerância e de VIF indicam que não existem problemas de multicolinearidade e os resultados são confiáveis, tendo em vista que os resíduos do modelo tiveram uma distribuição aproximadamente normal, de acordo com o Gráfico 6.

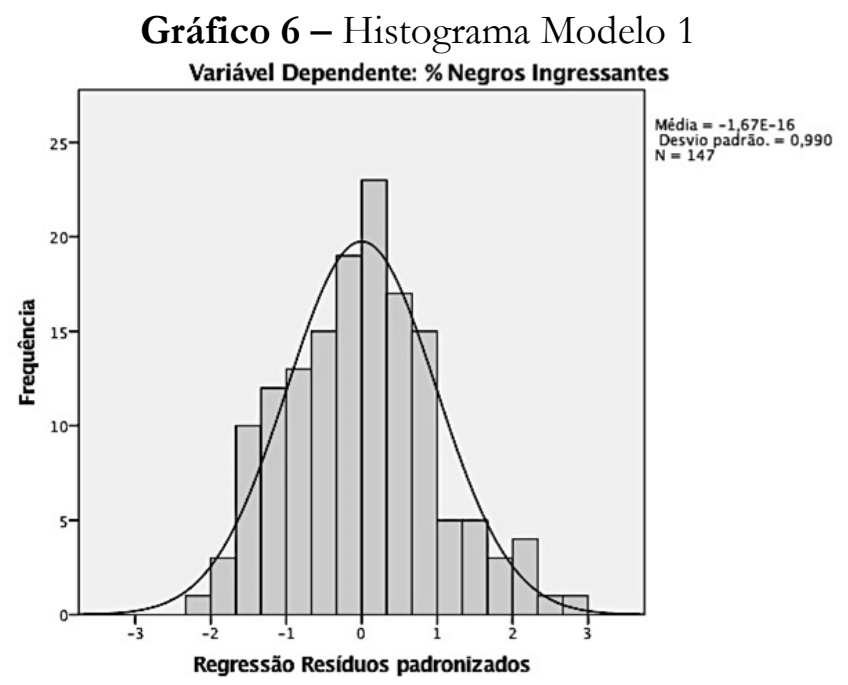




\section{Fontes:}

Censo da Educação Superior 2009 a 2015 (INEP, 2016a, 2016b, 2016c, 2016d, 2016e, 2016f, 2016g).

Pesquisa Nacional por Amostra de Domicílios (PNAD) 2009 e 2011 a 2015 (IBGE, 2010, 2012, 2013, 2015a, 2015b, 2016).

Censo Demográfico 2010 (IBGE, 2011).

${ }^{1}$ Calculado com o software IBM SPSS Statistics.

Modelo 2 - Variável Dependente: \% de ingressantes negros / Variáveis independentes: \% Negros UF, PANegros, PAEscolaPública

A indicação do valor de R2 mostra que as três variáveis, no seu conjunto, explicam 84,9\% do percentual de ingressantes negros, valor muito próximo ao R2 ajustado (Tabela 4).

Tabela 4 - Sumarização do modelo 2

\begin{tabular}{c|c|c|c|c} 
Modelo & R & R quadrado & R quadrado ajustado & Erro padrão da estimativa \\
\hline 2 &, $921^{1}$ &, 849 &, 846 & $8,5299 \%$ \\
\hline
\end{tabular}

\section{Fontes:}

Censo da Educação Superior 2009 a 2015 (INEP, 2016a, 2016b, 2016c, 2016d, 2016e, 2016f, 2016g).

Pesquisa Nacional por Amostra de Domicílios (PNAD) 2009 e 2011 a 2015 (IBGE, 2010, 2012, 2013, 2015a, 2015b, 2016).

Censo Demográfico 2010 (IBGE, 2011).

${ }^{1}$ Preditores: (Constante), \% Negros UF, PAEscolaPública, PANegros.

${ }^{2}$ Calculado com o software IBM SPSS Statistics.

A regressão mostra-se significativa $\operatorname{com} \mathrm{F}(3,143)=267,465 \mathrm{e} \mathrm{p}=0,000$ e indica que as três variáveis contribuem para a explicação de uma fração significativa da variação dos percentuais de ingressantes negros, conforme Quadro 5.

Quadro 5 - ANOVA do Modelo 2

\begin{tabular}{|c|c|c|c|c|c|c|}
\hline \multicolumn{2}{|c|}{ Modelo } & Soma dos Quadrados & gl & Quadrado Médio & F & Sig. \\
\hline \multirow{3}{*}{2} & Regressão & 58381,887 & 3 & 19460,629 & 267,465 &, 000 \\
\cline { 2 - 8 } & Resíduo & 10404,633 & 143 & 72,760 & & \\
\cline { 2 - 8 } & Total & 68786,520 & 146 & & & \\
\hline
\end{tabular}

\section{Fontes:}

Censo da Educação Superior 2009 a 2015 (INEP, 2016a, 2016b, 2016c, 2016d, 2016e, 2016f, 2016g).

Pesquisa Nacional por Amostra de Domicílios (PNAD) 2009 e 2011 a 2015 (IBGE, 2010, 2012, 2013, 2015a, 2015b, 2016).

Censo Demográfico 2010 (IBGE, 2011).

${ }^{1}$ Calculado com o software IBM SPSS Statistics.

O efeito de dois dos três preditores é significativo, de acordo com o Quadro 6. O efeito do percentual de negros no estado é bem superior, já que $\beta=0,972, t=28,175, p=0,000$, enquanto para política afirmativa para negros, $\beta=0,269, \mathrm{t}=5,341, \mathrm{p}=0,000$. Já a política afirmativa para escola pública não é significativa, $\operatorname{com} \beta=0,020, \mathrm{t}=0,414, \mathrm{p}=0,679$.

Quadro 6 - Coeficientes do Modelo 2

\begin{tabular}{|c|c|c|c|c|c|c|c|}
\hline \multirow{2}{*}{ Variáveis } & \multicolumn{2}{|c|}{$\begin{array}{l}\text { Coeficientes não } \\
\text { padronizados }\end{array}$} & \multirow{2}{*}{$\begin{array}{c}\begin{array}{c}\text { Coeficientes } \\
\text { padronizados }\end{array} \\
\text { Beta }\end{array}$} & \multirow{2}{*}{$\mathrm{t}$} & \multirow{2}{*}{ Sig. } & \multicolumn{2}{|c|}{ Estatísticas de colinearidade } \\
\hline & B & $\begin{array}{c}\text { Erro } \\
\text { Padrão }\end{array}$ & & & & Tolerância & VIF \\
\hline (Constante) & $-18,934$ & 2,335 & & $-8,108$ & ,000 & & \\
\hline PAEscolaPública & 1,001 & 2,416 & ,020 & ,414 & 679 & ,450 & 2,221 \\
\hline PANegros & 11,973 & 2,242 & 269 & 5,341 &, 000 & ,418 & 2,394 \\
\hline$\%$ Negros UF & ,918 & ,033 & 972 & 28,175 &, 000 & ,889 & 1,124 \\
\hline
\end{tabular}


Fontes:

Censo da Educação Superior 2009 a 2015 (INEP, 2016a, 2016b, 2016c, 2016d, 2016e, 2016f, 2016g).

Pesquisa Nacional por Amostra de Domicílios (PNAD) 2009 e 2011 a 2015 (IBGE, 2010, 2012, 2013, 2015a, 2015b, 2016).

Censo Demográfico 2010 (IBGE, 2011).

${ }^{1}$ Calculado com o software IBM SPSS Statistics.

Os valores de Tolerância e de VIF indicam que não existem problemas de multicolinearidade e que os resultados são confiáveis, tendo em vista que os resíduos do modelo apresentaram uma distribuição aproximadamente normal, conforme Gráfico 7.

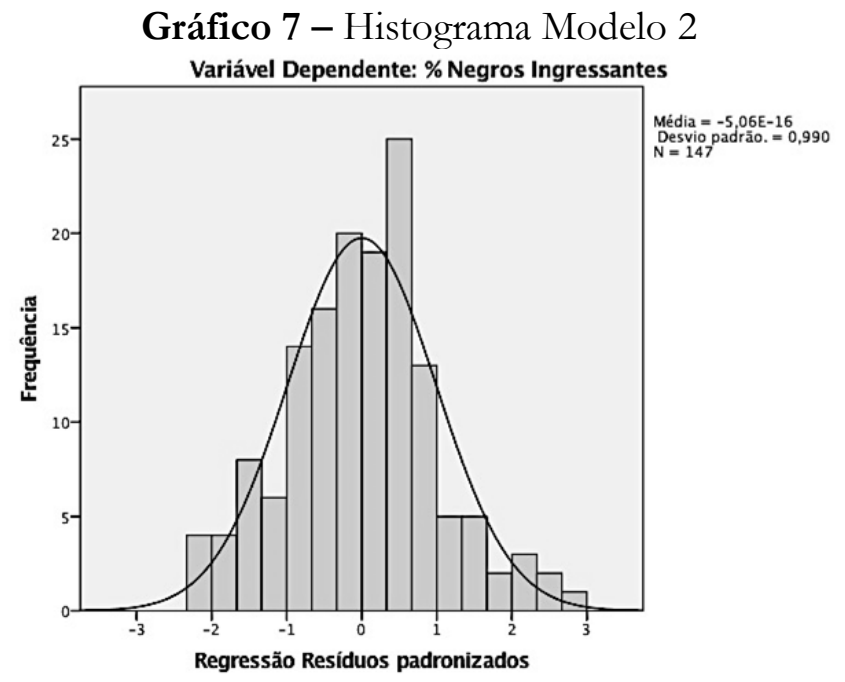

\footnotetext{
Fontes:

Censo da Educação Superior 2009 a 2015 (INEP, 2016a, 2016b, 2016c, 2016d, 2016e, 2016f, 2016g).

Pesquisa Nacional por Amostra de Domicílios (PNAD) 2009 e 2011 a 2015 (IBGE, 2010, 2012, 2013, 2015a, 2015b, 2016).

Censo Demográfico 2010 (IBGE, 2011).
}

Modelo 3 - Variável Dependente: \% de ingressantes negros / Variáveis independentes: \% Negros UF, \% Vagas Reservadas Escola Pública, \% Vagas Reservadas Negros

A indicação do valor de R2 mostra que as três variáveis, no seu conjunto, explicam $86,8 \%$ do percentual de ingressantes negros, valor muito próximo ao R2 ajustado (Tabela 5).

Tabela 5 - Sumarização do modelo 3

\begin{tabular}{c|c|c|c|c}
\hline Modelo & $\mathrm{R}$ & R quadrado & R quadrado ajustado & Erro padrão da estimativa \\
\hline 3 &, 931 &, 868 &, 865 & $8,0916 \%$ \\
\hline
\end{tabular}

Fontes:

Censo da Educação Superior 2009 a 2015 (INEP, 2016a, 2016b, 2016c, 2016d, 2016e, 2016f, 2016g).

Pesquisa Nacional por Amostra de Domicílios (PNAD) 2009 e 2011 a 2015 (IBGE, 2010, 2012, 2013, 2015a, 2015b, 2016)

Censo Demográfico 2010 (IBGE, 2011).

${ }^{1}$ Preditores: (Constante), \% Negros UF, \% Vagas Reservadas Negros, \% Vagas Reservadas Escola Pública.

${ }^{2}$ Calculado com o software IBM SPSS Statistics.

A regressão mostra-se significativa $\operatorname{com} \mathrm{F}(3,136)=297,095$ e $\mathrm{p}=0,000$ e indica que as três variáveis contribuem para a explicação de uma fração significativa da variação dos percentuais de ingressantes negros, de acordo com o Quadro 7. 
Quadro 7 - ANOVA do Modelo 3

\begin{tabular}{|c|c|c|c|c|c|c|}
\hline \multicolumn{2}{|c|}{ Modelo } & Soma dos Quadrados & gl & Quadrado Médio & F & Sig. \\
\hline \multirow{3}{*}{3} & Regressão & 58356,135 & 3 & 19452,045 & 297,095 &, 000 \\
\cline { 2 - 7 } & Resíduo & 8904,490 & 136 & 65,474 & & \\
\cline { 2 - 7 } & Total & 67260,625 & 139 & & & \\
\hline
\end{tabular}

\section{Fontes:}

Censo da Educação Superior 2009 a 2015 (INEP, 2016a, 2016b, 2016c, 2016d, 2016e, 2016f, 2016g).

Pesquisa Nacional por Amostra de Domicílios (PNAD) 2009 e 2011 a 2015 (IBGE, 2010, 2012, 2013, 2015a, 2015b, 2016).

Censo Demográfico 2010 (IBGE, 2011).

${ }^{1}$ Calculado com o software IBM SPSS Statistics.

O efeito de dois dos três preditores é significativo, conforme Quadro 8. O efeito do percentual de negros no estado é bem superior, pois $\beta=0,844, t=22,177, p=0,000$, enquanto para $\%$ de vagas reservadas para negros, $\beta=0,292, \mathrm{t}=8,873, \mathrm{p}=0,000$. Já o $\%$ de vagas reservadas para escola pública não é significativo, $\operatorname{com} \beta=0,053, \mathrm{t}=1,412, \mathrm{p}=0,160$.

Quadro 8 - Coeficientes do Modelo 3

\begin{tabular}{|c|c|c|c|c|c|c|c|}
\hline \multirow{2}{*}{ Variáveis } & \multicolumn{2}{|c|}{$\begin{array}{l}\text { Coeficientes não } \\
\text { padronizados }\end{array}$} & \multirow{2}{*}{$\begin{array}{c}\text { Coeficientes } \\
\text { padronizados } \\
\text { Beta }\end{array}$} & \multirow{2}{*}{$\mathrm{t}$} & \multirow{2}{*}{ Sig. } & \multicolumn{2}{|c|}{ Estatísticas de colinearidade } \\
\hline & B & $\begin{array}{l}\text { Erro } \\
\text { Padrão }\end{array}$ & & & & Tolerância & VIF \\
\hline (Constante) & $-12,038$ & 2,313 & & $-5,204$ &, 000 & & \\
\hline $\begin{array}{c}\text { \% Vagas Reservadas } \\
\text { Escola Pública }\end{array}$ & ,072 & ,051 & ,053 & 1,412 & ,160 & ,700 & 1,429 \\
\hline $\begin{array}{c}\% \text { Vagas Reservadas } \\
\text { Negros }\end{array}$ & 616 & ,069 & ,292 & 8,873 &, 000 & ,896 & 1,116 \\
\hline$\%$ Negros UF & ,802 & 036 & ,844 & 22,177 &, 000 & ,672 & 1,489 \\
\hline
\end{tabular}

\section{Fontes:}

Censo da Educação Superior 2009 a 2015 (INEP, 2016a, 2016b, 2016c, 2016d, 2016e, 2016f, 2016g).

Pesquisa Nacional por Amostra de Domicílios (PNAD) 2009 e 2011 a 2015 (IBGE, 2010, 2012, 2013, 2015a, 2015b, 2016).

Censo Demográfico 2010 (IBGE, 2011).

${ }^{1}$ Calculado com o software IBM SPSS Statistics.

Os valores de Tolerância e de VIF indicam que não existem problemas de multicolinearidade e que os resultados são confiáveis, tendo em vista que os resíduos do modelo tiveram uma distribuição aproximadamente normal, conforme Gráfico 8.

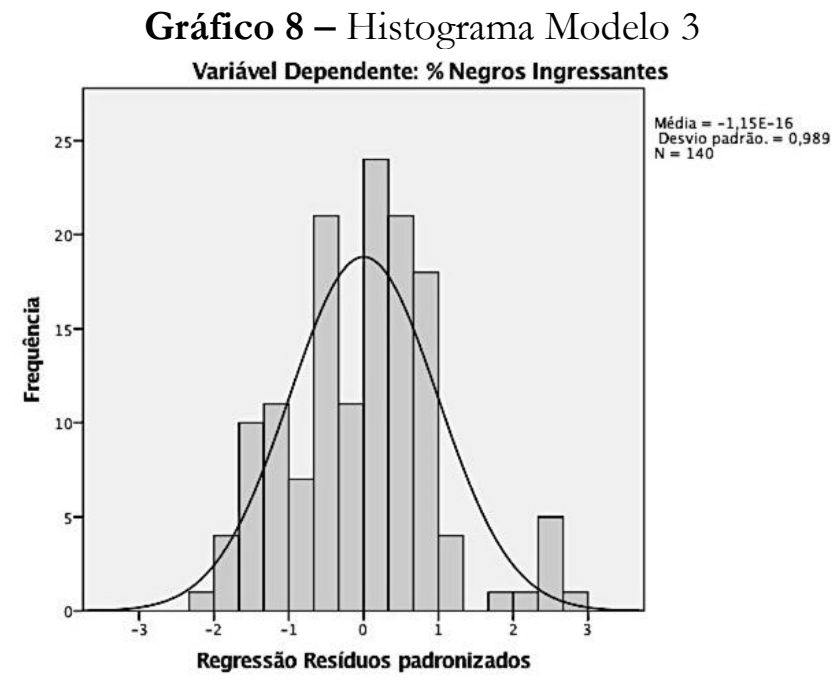




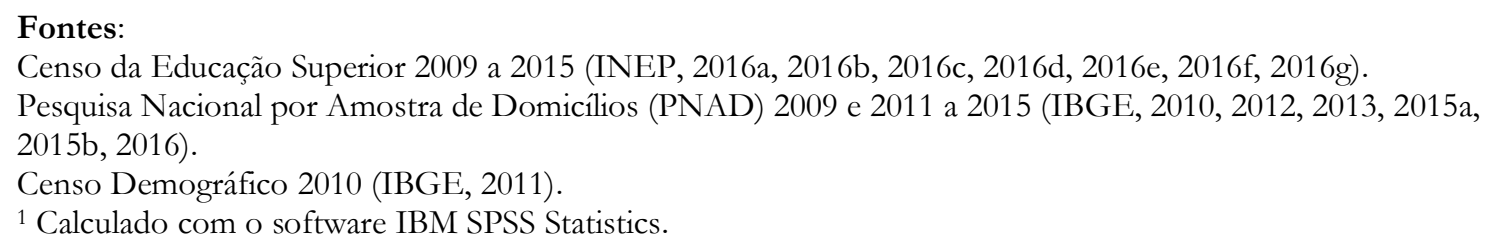

O modelo 3 foi o que apresentou maior percentual explicativo, indicando que, mais do que a simples presença de políticas afirmativas, o percentual de vagas reservadas é o que mais influencia o percentual de ingressantes negros nas instituições de ensino superior. O percentual reservado para negros diminui o percentual explicativo do percentual de negros no estado, apesar de este permanecer como principal explicação. Já a política afirmativa para escolas públicas se mostrou insignificante nos dois modelos, e a política nacional mostrou-se mais significativa do que as políticas locais.

Tal conclusão reforça o apontado por Daflon, Feres Júnior e Campos (2013) quando destacam que, ao contrário do que postulam aqueles que defendem políticas estritamente sociais, a sobreposição entre negritude e pobreza não necessariamente torna a ação afirmativa baseada exclusivamente na classe um mecanismo eficaz de inclusão de grupos etnicorraciais discriminados. Segundo os autores, quando as ações afirmativas baseiam-se apenas no critério da renda familiar, o número de potenciais beneficiários provenientes dos grupos etnicorraciais discriminados cai substantivamente, e se eleva o percentual de potenciais beneficiários de grupos que não sofrem discriminação. Já quando a admissão se baseia em critérios etnicorraciais, essas políticas realmente beneficiam membros de grupos discriminados, e o objetivo da política afirmativa é, portanto, alcançado de forma mais eficaz.

\section{CONCLUSÃO}

A Lei Afonso Arinos, de 1951, foi a primeira a tipificar o racismo como contravenção penal. Somente com a Constituição de 1988, o racismo foi elevado a crime inafiançável, imprescritível e sujeito à pena de reclusão. A Lei $\mathrm{n}^{\mathrm{o}} 7.716 / 89$ disciplinou os crimes resultantes de preconceito de raça e cor, sendo alterada, em 1997, para também contemplar a injúria baseada em discriminação racial. No entanto, a aplicabilidade dessas leis é muito limitada, e o racismo ainda é forte no País.

As comparações do racismo no Brasil e nos Estados Unidos muitas vezes ignoram que, nos EUA, apenas $10 \%$ da população é negra, enquanto no Brasil esse percentual chega a $51 \%$, não sendo possível que metade da população fique fora da economia do País. Assim, quando se argumenta que os EUA aboliram a reserva de vagas para negros no ensino superior, esquece-se que esse formato de ação afirmativa esteve em vigor naquele país por cinco décadas e que foram mantidas outras formas de políticas de afirmativas para esse nível de ensino.

A discussão sobre como combater o racismo é antiga, e as primeiras discussões sobre ações afirmativas no País ocorrem desde pelo menos 1995, ou seja, há mais de vinte anos. Somente no início do século 21, o Estado brasileiro começou a tomar um conjunto de medidas práticas com vistas a enfrentar o racismo e a reduzir as desigualdades entre negros e brancos. O debate sobre a reserva de vagas nas instituições federais de ensino superior acontecia com força dentro do governo brasileiro ao menos desde 2001. Mesmo assim, a política afirmativa para as instituições federais de ensino superior só foi aprovada pelo Congresso Nacional e sancionada pela Presidente da República em 2012.

Nas instituições analisadas neste estudo, o percentual de alunos brancos apresentou uma queda de 8,2\% no período de 2009 a 2015, de acordo o Gráfico 9. Enquanto isso, o percentual de alunos negros cresceu 56,3\%. O percentual de alunos negros cresceu $21,1 \%$, de 2009 a 2012; e 29,1\%, de 2012 a 2015 . 
Gráfico 9-Distribuição percentual de alunos das Instituições Federais que compuseram a amostra final desta pesquisa

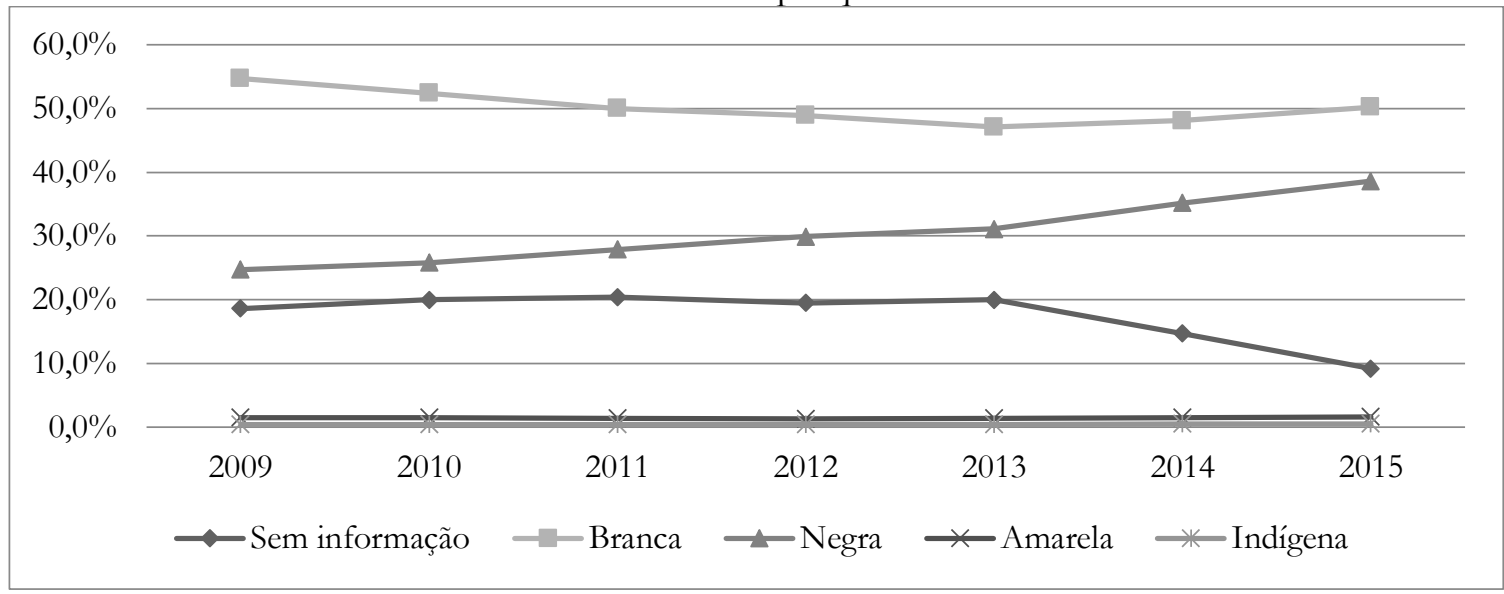

Fonte: Censo da Educação Superior 2009 a 2015 (INEP, 2016a, 2016b, 2016c, 2016d, 2016e, 2016f, 2016g).

Já entre os ingressantes, as instituições analisadas apresentaram aumento de 1,4\% para brancos e aumento de $61,4 \%$ para negros (Gráfico 10). Os ingressantes negros apresentaram crescimento de $24,7 \%$, de 2009 a 2012; e de $29,4 \%$, de 2012 a 2015.

Gráfico 10 - Distribuição percentual de alunos ingressantes das Instituições Federais que compuseram a amostra final desta pesquisa

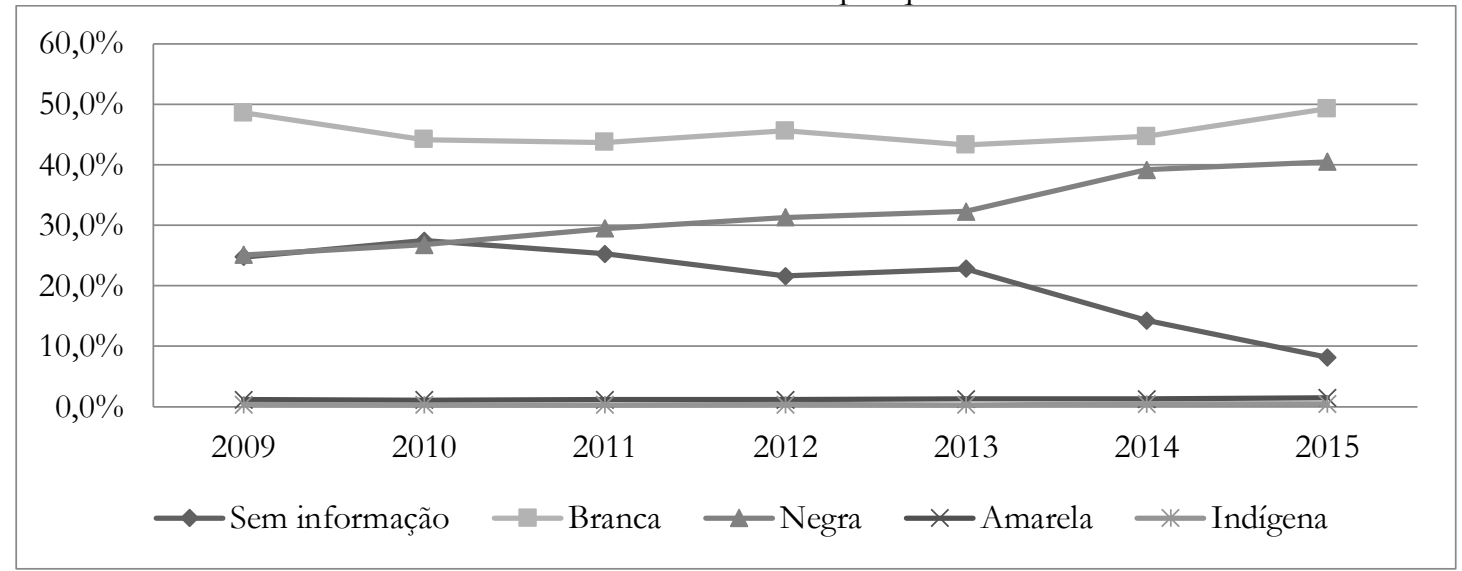

Fonte: Censo da Educação Superior 2009 a 2015 (INEP, 2016a, 2016b, 2016c, 2016d, 2016e, 2016f, 2016g).

Ressalta-se que a diminuição do percentual de alunos sem informação e, em contrapartida, aumentos nos percentuais de negros, mas também de brancos, ainda que em menor grau, podem indicar que a política pública afetou as maneiras de os alunos identificarem sua cor ou raça, diminuindo a refração à própria classificação racial. Apesar de este ponto não ter sido o foco do estudo, essa é uma hipótese a ser estudada em futuras pesquisas.

Entre os concluintes, a mudança na distribuição percentual dos alunos por cor ou raça é menor, mas perceptível (Gráfico 11). Houve uma queda de 5,8\% no percentual de concluintes brancos e um aumento de 33,2\% no de negros. De 2009 a 2012, aumentou 19,3\% o percentual de concluintes negros e, de 2012 a 2015, o percentual cresceu $11,7 \%$. 
Gráfico 11 - Distribuição percentual de alunos concluintes das Instituições Federais que compuseram a amostra final desta pesquisa

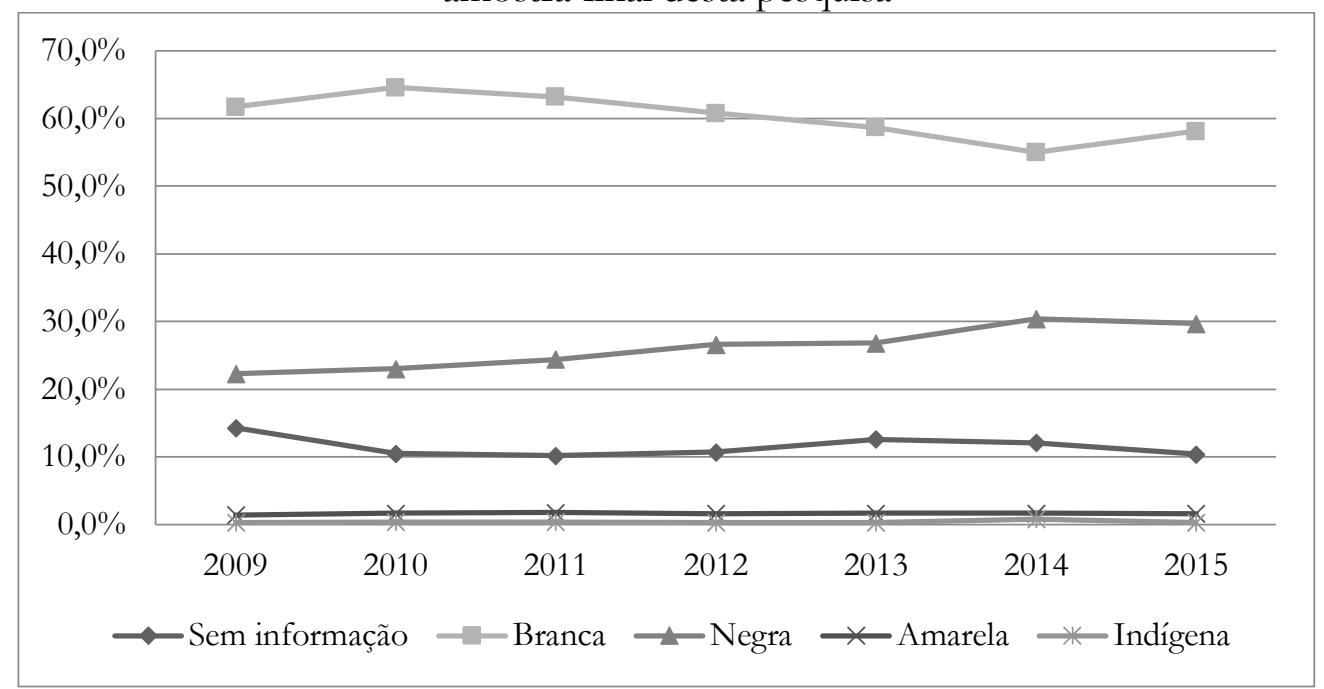

Fonte: Censo da Educação Superior 2009 a 2015 (INEP, 2016a, 2016b, 2016c, 2016d, 2016e, 2016f, 2016g).

O principal fator explicativo para o percentual de ingressantes negros nas instituições é o percentual de negros no estado, que também é o que define os percentuais de vagas reservadas pela política afirmativa nacional.

As análises quantitativas mostraram que a política nacional influencia o percentual de ingressantes negros nas instituições federais de ensino superior, em diferentes graus. Com um R2 de 0,828 , o efeito da política nacional é significativo para o percentual de ingressantes negros $(\beta=0,277, \mathrm{t}$ $=6,185, \mathrm{p}=0,000)$.

Com um R2 de 0,849, o efeito da variável política afirmativa para negros $(\beta=0,269, \mathrm{t}=$ $5,341, \mathrm{p}=0,000)$ é significativo, enquanto a variável política afirmativa para escola pública não é significativa $(\beta=0,020, \mathrm{t}=0,414, \mathrm{p}=0,679)$.

Com maior R2 $(0,868)$ dos três modelos, o segundo fator que mais influencia o percentual de ingressantes negros é o percentual de vagas reservadas para negros $(\beta=0,292, \mathrm{t}=8,873, \mathrm{p}=0,000)$, definido pelo percentual de negros no estado, que volta a ser o centro de influência. Já o percentual de vagas reservadas para escola pública não foi significativo nesse modelo $(\beta=0,053, t=1,412, p=0,160)$.

Assim, não há indícios de que a reserva de vagas para escola pública seja suficiente para a ampliação do acesso à população negra e para a diminuição da desigualdade, já que, apesar de a associação entre as variáveis existir, não é significativa. Por outro lado, a política nacional e, mais ainda, o percentual de vagas reservadas para negros, demonstram que a política afirmativa definida pela Lei no 12.711/2012 vem sendo efetiva.

Considerando que a análise abarca apenas três anos de implementação da política e que a implantação só foi finalizada em 2016, cujos dados ainda não estão disponíveis, ressalta-se que é muito significativo o efeito para o aumento do acesso ao ensino superior para a população negra.

Por outro lado, um ponto que vale a pena destacar, e que confirma as preocupações em torno do desenho da política afirmativa nacional, é que os alunos negros continuam se concentrando nos cursos menos disputados nos vestibulares e com salários dos profissionais também mais baixos. Os cursos mais disputados e com mais retorno salarial continuam refratários à essa população. Não foi escopo desta pesquisa, mas deve ser objeto de estudos, a questão das motivações para a persistência dessas diferenças.

Ressaltam-se, também, as limitações deste estudo tendo em vista a quantidade de dados sem informação no Censo da Educação Superior, bem como a ausência de controle sobre a coleta dos dados, uma vez que cada instuição faz o preenchimento das informações segundo seus próprios critérios. Além disso, a utilização de variáveis dummy para análise dos dados ao mesmo tempo que permite uma avaliação mais ampla dos dados, limita a profundidade da análise. Também não é possível eliminar a 
influência de variáveis externas para a explicação dos resultados, apesar dos esforços empregados para diminuir essa possibilidade.

As principais críticas às ações afirmativas sempre sustentaram que, em vez de políticas afirmativas, o Estado deveria melhorar a educação pública para que todos pudessem competir em igualdade de condições. Porém, passaram-se mais de vinte anos, e muitos ainda continuam com esse discurso. Assim, caso não tivessem sido implantadas ações afirmativas, mais uma geração inteira teria permanecido excluída do acesso ao ensino superior e, provavelmente, assim ficaria por mais vinte anos, considerando que até hoje a educação básica pública é sofrível.

Se brancos têm pais com mais anos de estudo, maior renda, acesso à educação de mais qualidade, maior acesso à cultura, livros e bibliotecas, como é possível argumentar que a igualdade de condições é uma prova de um vestibular cego às diferenças? $O$ vestibular tradicional mede a qualidade do sistema escolar e das condições sociais, e não o mérito dos estudantes.

Um dos principais obstáculos à democracia é a distância entre a lei e a sua efetividade. No Brasil, apesar de existir liberdade e igualdade formais, há uma tradição discriminadora, hierárquica e preconceituosa, comprometendo a efetividade da democracia. Só políticas desiguais para os desiguais são capazes de levar a uma igualdade efetiva. O Brasil precisa romper a visão formalista para poder reduzir as desigualdades e combater verdadeiramente o racismo no País.

\section{REFERÊNCIAS}

ALBERTI, V.; PEREIRA, A. A. As Articulações entre movimento negro e Estado: estratégias e experiências contemporâneas. In: GOMES, Angela C. (Org). Direitos e cidadania: memória, política e cultura. Rio de Janeiro: FGV, p. 93-113, 2007.

ALBERTI, V.; PEREIRA, A. A. Movimento negro e "democracia racial" no Brasil: entrevistas com lideranças do movimento negro. Rio de Janeiro: CPDOC, 2005.

ALVES, M. A.; GALEÃO-SILVA, L. G. A crítica da gestão da diversidade nas organizações. Revista de Administração de Empresas (RAE), São Paulo, v. 44, n. 3, p. 20-29, 2004.

ARAÚjO, J. Z. O Negro na Dramaturgia, um Caso Exemplar da Decadência do Mito da Democracia Racial Brasileira. Estudos Feministas, Florianópolis, n. 16, v. 3, p. 979-985, set./dez., 2008.

BERNARDinO, J. Ação Afirmativa e a Rediscussão do Mito da Democracia Racial no Brasil. Estudos Afro-Asiáticos, a. 24, n. 2, p. 247-273, 2002.

BRASIL. Supremo Tribunal Federal. Ação direta de inconstitucionalidade no 3197/RJ - Rio de Janeiro.

Relator: Celso de Mello. Pesquisa de Jurisprudência. Disponível em:

http://www.stf.jus.br/portal/processo/verProcessoAndamento.asp?incidente=2218262. Acesso em: 25 jan. 2017.

BRASIL. Supremo Tribunal Federal. Ação direta de inconstitucionalidade no 3330/DF - Distrito Federal. Relator: Ayres Britto. Pesquisa de Jurisprudência. Disponível em: http://www.stf.jus.br/portal/processo/verProcessoAndamento.asp?incidente=2251887. Acesso em: 25 jan. 2017.

BRASIL. Supremo Tribunal Federal. Ação direta de inconstitucionalidade no 3314/DF - Distrito Federal. Relator: Ayres Britto. Pesquisa de Jurisprudência. Disponível em: http://www.stf.jus.br/portal/processo/verProcessoAndamento.asp?incidente=2248290. Acesso em: 25 jan. 2017. 
BRASIL. Supremo Tribunal Federal. Ação direta de inconstitucionalidade no 3379/DF - Distrito Federal. Relator: Ayres Britto. Pesquisa de Jurisprudência. Disponível em:

http://www.stf.jus.br/portal/processo/verProcessoAndamento.asp?incidente=2262461. Acesso em: 25 jan. 2017.

BRASIL. Supremo Tribunal Federal. Arguição de Descumprimento de Preceito Fundamental n ${ }^{\circ}$ 186/DF - Distrito Federal. Relator: Ricardo Lewandowski. Pesquisa de Jurisprudência. Disponível em:

http:/ /www.stf.jus.br/portal/processo/verProcessoAndamento.asp?numero=186\&classe $=$ ADPF\&co digoClasse $=0 \&$ origem $=J U R \&$ recurso $=0 \&$ tipoJulgamento $=\mathrm{M}$. Acesso em: 25 jan. 2017.

BRASIL. Supremo Tribunal Federal. Recurso Extraordinário no 597285/RS - Rio Grande do Sul. Relator: Ricardo Lewandowski. Pesquisa de Jurisprudência. Disponível em:

http://www.stf.jus.br/portal/processo/verProcessoAndamento.asp?numero $=597285 \&$ classe $=$ RE\&co digoClasse $=0 \&$ origem $=J U R \&$ recurso $=0 \&$ tipoJulgamento $=$ M. Acesso em: 25 jan. 2017.

CAMPOS, L. A.; FERES JÚNIOR, J.; DAFLON, V. T. O Desempenho dos Cotistas no ENEM: comparando as notas de corte do SISU. Textos para discussão GEMAA (IESPUERJ), n. 4, pp. 123, 2014.

DAFLON, V. T.; FERES JÚNIOR, J. CAMPOS, L. A. Ações afirmativas raciais no ensino superior público brasileiro: um panorama analítico. Cadernos de Pesquisa, v.43 n.148, p.302-327, jan./abr. 2013.

DAHER FILHO, A; MARIANO, A.; AGGIO, A.; MELLO E SOUZA, A. D.; LIMA, A. da S.; GOMES, A.; VENANCIO, A. T. Todos têm direitos iguais na República. Folha de S. Paulo, São Paulo, 29 jun. 2006. Disponível em: http://www1.folha.uol.com.br/fsp/opiniao/fz2906200608.htm. Acesso em: 05 fev. 2016.

DAHER, A.; et al. Cidadãos antirracistas contra as leis raciais. Folha de S. Paulo, São Paulo, 14 mai. 2008. Disponível em: http://www1.folha.uol.com.br/fsp/cotidian/ff1405200807.htm. Acesso em: 24 jan. 2017.

GUARNIERI, F. V.; MELO-SILVA, L. L. Ações afirmativas na educação superior: rumos da discussão nos últimos cinco anos. Psicologia \& Sociedade, n. 19, v. 2, p. 70-78, 2007.

GUIMARÃES, A. S. A. Racismo e antirracismo no Brasil. Novos Estudos, CEBRAP, n. 43, p. 2644, nov. 1995.

INSTITUTO BRASILEIRO DE GEOGRAFIA e ESTATÍSTICA - IBGE. Características étnicoraciais da população: um estudo das categorias de classificação de cor ou raça. Rio de Janeiro, 2011. Disponível em: https://biblioteca.ibge.gov.br/visualizacao/livros/liv49891.pdf. Acesso em: 3 set. 2020.

INSTITUTO BRASILEIRO DE GEOGRAFIA e ESTATÍSTICA - IBGE. Censo Demográfico 2010. Rio de Janeiro, 2011.

INSTITUTO BRASILEIRO DE GEOGRAFIA e ESTATÍSTICA - IBGE. Pesquisa Nacional por Amostra de Domicílios 2009. Rio de Janeiro, 2010. Disponível em: https://biblioteca.ibge.gov.br/visualizacao/livros/liv49891.pdf. Acesso em: 3 set. 2020.

INSTITUTO BRASILEIRO DE GEOGRAFIA e ESTATÍSTICA - IBGE. Pesquisa Nacional por Amostra de Domicílios 2011. Rio de Janeiro, 2012. Disponível em: 
https://biblioteca.ibge.gov.br/visualizacao/livros/liv49891.pdf. Acesso em: 3 set. 2020.

INSTITUTO BRASILEIRO DE GEOGRAFIA e ESTATÍSTICA - IBGE. Pesquisa Nacional por Amostra de Domicílios 2012. Rio de Janeiro, 2013. Disponível em:

https://biblioteca.ibge.gov.br/visualizacao/livros/liv49891.pdf. Acesso em: 3 set. 2020.

INSTITUTO BRASILEIRO DE GEOGRAFIA e ESTATÍSTICA - IBGE. Pesquisa Nacional por Amostra de Domicílios 2013. Rio de Janeiro, 2015a. Disponível em: https://biblioteca.ibge.gov.br/visualizacao/livros/liv49891.pdf. Acesso em: 3 set. 2020.

INSTITUTO BRASILEIRO DE GEOGRAFIA e ESTATÍSTICA - IBGE. Pesquisa Nacional por Amostra de Domicílios 2014. Rio de Janeiro, 2015b. Disponível em: https://biblioteca.ibge.gov.br/visualizacao/livros/liv49891.pdf. Acesso em: 3 set. 2020.

INSTITUTO BRASILEIRO DE GEOGRAFIA e ESTATÍSTICA - IBGE. Pesquisa Nacional por Amostra de Domicílios 2015. Rio de Janeiro, 2016. Disponível em:

https://www.ibge.gov.br/estatisticas/sociais/educacao/9127-pesquisa-nacional-por-amostra-dedomicilios.html? $=\& \mathrm{t}=\mathrm{O}$-que-e. Acesso em: 3 set. 2020.

INSTITUTO DE PESQUISA ECONÔMICA APLICADA - IPEA. Retrato das desigualdades de gênero e raça - 1995 a 2013. Com a participação de: ONU Mulheres, Secretaria de Políticas para as Mulheres (SPM). Brasília, 2014. Disponível em: http://www.IPEA.gov.br/retrato/indicadores.html. Acesso em: 16 jan. 2015.

INSTITUTO NACIONAL DE ESTUDOS e PESQUISAS EDUCACIONAIS ANÍSIO TEIXEIRA - INEP. Microdados do Censo da Educação Superior 2009. Brasília, 2016a. Disponível em: http://download.INEP.gov.br/microdados/microdados_censo_superior_2009.zip. Acesso em: 13 jun. 2016.

INSTITUTO NACIONAL DE ESTUDOS e PESQUISAS EDUCACIONAIS ANÍSIO TEIXEIRA - INEP. Microdados do Censo da Educação Superior 2010. Brasília, 2016b. Disponível em: http://download.INEP.gov.br/microdados/microdados_censo_superior_2010.zip. Acesso em: 13 jun. 2016.

INSTITUTO NACIONAL DE ESTUDOS e PESQUISAS EDUCACIONAIS ANÍSIO TEIXEIRA - INEP. Microdados do Censo da Educação Superior 2011. Brasília, 2016c. Disponível em: http://download.INEP.gov.br/microdados/microdados_censo_superior_2011.zip. Acesso em: 13 jun. 2016.

INSTITUTO NACIONAL DE ESTUDOS e PESQUISAS EDUCACIONAIS ANÍSIO TEIXEIRA - INEP. Microdados do Censo da Educação Superior 2012. Brasília, 2016d. Disponível em: http://download.INEP.gov.br/microdados/microdados_censo_superior_2012.zip. Acesso em: 13 jun. 2016.

INSTITUTO NACIONAL DE ESTUDOS e PESQUISAS EDUCACIONAIS ANÍSIO TEIXEIRA - INEP. Microdados do Censo da Educação Superior 2013. Brasília, 2016e. Disponível em: http://download.INEP.gov.br/microdados/microdados_censo_superior_2013.zip. Acesso em: 13 jun. 2016.

INSTITUTO NACIONAL DE ESTUDOS e PESQUISAS EDUCACIONAIS ANÍSIO TEIXEIRA - INEP. Microdados do Censo da Educação Superior 2014. Brasília, 2016f. Disponível em: http://download.INEP.gov.br/microdados/microdados_censo_superior_2014.zip. Acesso em: 13 jun. 2016. 
INSTITUTO NACIONAL DE ESTUDOS e PESQUISAS EDUCACIONAIS ANÍSIO TEIXEIRA - INEP. Microdados do Censo da Educação Superior 2015. Brasília, 2016g. Disponível em: http://download.INEP.gov.br/microdados/microdados_censo_superior_2015.zip. Acesso em: 18 nov. 2016.

MOEHLECKE, S. Ação afirmativa no ensino superior: entre a excelência e a justiça racial. Educação e Sociedade, Campinas, v. 25, n. 88, p. 757-776, Out. 2004.

NASCIMENTO, A.; et al. Manifesto em defesa da justiça e constitucionalidade das cotas. Folha de S. Paulo, São Paulo, 14 mai. 2008. Disponível em: http://www1.folha.uol.com.br/fsp/cotidian/ff1405200808.htm. Acesso em: 24 jan. 2017.

OLIVEIRA FILHO, P. de. A mobilização do discurso da democracia racial no combate às cotas para afrodescendentes. Estudos de Psicologia, Campinas, v. 26, n. 4, p. 429-436, out./dez. 2009.

PEREIRA, A. M. "Um raio em céu azul". Reflexões sobre a política de cotas e a identidade nacional brasileira. Estudos Afro-asiáticos, a.25, n. 3, p. 463-482, 2003.

PINTO, P. G. H. R. Ação Afirmativa, Fronteiras Raciais e Identidades Acadêmicas: Uma Etnografia das Cotas Para Negros na UERJ. Paper apresentado na I Conferência Internacional da Rede de Estudos sobre Ação Afirmativa, Universidade Cândido Mendes, Rio de Janeiro, jan. 2005. Disponível em: http://aasn.iuperj.br/Articles/Paulo_Gabriel_Hilu.pdf. Acesso em: 05 fev. 2016.

RAWLS, J. Uma teoria da justiça. São Paulo: Martins Fontes, 2008.

Submetido: $21 / 08 / 2019$

Aprovado: 13/09/2020 